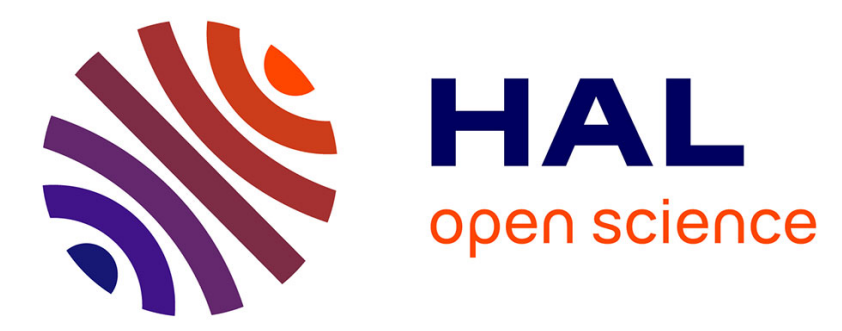

\title{
Mineralogy and petrology of the angrite Northwest Africa 1296
}

Albert Jambon, Jean-Alix J-A Barrat, Omar Boudouma, Michel Fonteilles, D. Badia, C. Göpel, Marcel Bohn

\section{- To cite this version:}

Albert Jambon, Jean-Alix J-A Barrat, Omar Boudouma, Michel Fonteilles, D. Badia, et al.. Mineralogy and petrology of the angrite Northwest Africa 1296. Meteoritics and Planetary Science, 2005, 40 (3), pp.361-375. hal-00113853

\section{HAL Id: hal-00113853 \\ https://hal.science/hal-00113853}

Submitted on 2 May 2011

HAL is a multi-disciplinary open access archive for the deposit and dissemination of scientific research documents, whether they are published or not. The documents may come from teaching and research institutions in France or abroad, or from public or private research centers.
L'archive ouverte pluridisciplinaire HAL, est destinée au dépôt et à la diffusion de documents scientifiques de niveau recherche, publiés ou non, émanant des établissements d'enseignement et de recherche français ou étrangers, des laboratoires publics ou privés. 


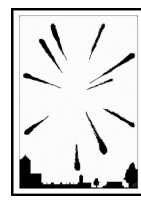

Meteoritics \& Planetary Science 40, Nr 3, 361-375 (2005)

Abstract available online at http://meteoritics.org

\title{
Mineralogy and petrology of the angrite Northwest Africa 1296
}

\author{
A. JAMBON,${ }^{1}$ J. A. BARRAT, ${ }^{2}$ O. BOUDOUMA,${ }^{3}$ M. FONTEILLES,${ }^{4}$ D. BADIA, ${ }^{1}$ \\ C. GÖPEL, ${ }^{5}$ and M. BOHN ${ }^{6}$
}

${ }^{1}$ Laboratoire Magie, Université Pierre et Marie Curie, CNRS UMR 7047, case 110, 4 place Jussieu, 75252 Paris cedex 05, France ${ }^{2}$ UBO-IUEM, CNRS UMR 6538, Place Nicolas Copernic, F29280 Plouzané, France

${ }^{3}$ Service du MEB, UFR des Sciences de la Terre, Université Pierre et Marie Curie, case 110, 4 place Jussieu, 75252 Paris cedex 05, France ${ }^{4}$ Pétrologie, Modélisation des Matériaux et Processus, Université Pierre et Marie Curie, case 110, 4 place Jussieu, 75252 Paris cedex 05, France

${ }^{5}$ Laboratoire de Géochimie et Cosmochimie, Institut de Physique du Globe, CNRS UMR 7579, 4 place Jussieu, 75252 Paris cedex 05, France ${ }^{6}$ Ifremer-Centre de Brest, CNRS-UMR 6538, BP70, 29280 Plouzané Cedex, France

*Corresponding author. E-mail: jambon@ccr.jussieu.fr

(Received 7 April 2004; revision accepted 18 January 2004)

\begin{abstract}
We report on a new angrite, Northwest Africa (NWA) 1296, a fine-grained rock with a magmatic texture of rapid cooling. Dendritic olivine $\left(\approx \mathrm{Fo}_{50}\right)$ crystallized first in association with anorthite microcrysts $\left(\mathrm{An}_{98-100}\right)$ forming composite chains separated from one another by intergrown Al-Fe diopside-hedenbergite pyroxenes. In addition, some olivines with lower Mg\# and increased $\mathrm{CaO}$ (up to $12 \%$ ) are found between the chains as equant microphenocrysts. Pyroxenes and olivines are both normally zoned from $\mathrm{Mg} \#=0.52$ to less than 0.01 in the rims. Ca-rich olivines are surrounded by, intergrown with, or replaced by subcalcic kirschsteinite. They appear after plagioclase crystallization stopped, at the end of the crystallization sequence. Minor phases are pyrrhotite, Fapatite, and titanomagnetite. Pyroxene is the last silicate phase to grow, interstitial to idiomorphic olivine-kirschsteinite. Numerous small vesicles and some channels are filled with microcristalline carbonate. The mode (vol $\%$ ) is about $28 \%$ olivine, $3 \%$ kirschsteinite, $32 \%$ anorthite, $34 \%$ pyroxene, and 3\% of the minor phases - close to that reported previously for D'Orbigny and Sahara (SAH) 99555. The bulk chemical composition of NWA 1296 is similar to D'Orbigny and SAH 99555; NWA 1296 differs by its texture and mineralogy, which are interpreted as resulting from rapid crystallization - an evidence of impact melting. Angrites cannot be produced by partial melting of a $\mathrm{CV}$ source because segregation of a "planetary" core is necessary to explain the low $\mathrm{FeO} / \mathrm{MgO}$ ratio of magnesian olivines. Neither the odd $\mathrm{Ca} / \mathrm{Al}$ ratio nor the very low $\mathrm{SiO}_{2}$ content can be explained by conventional partial melting scenarios. We suggest that carbonate is the key to angrite genesis. This is supported by the striking similarities with terrestrial melilitites $\left(\right.$ low $\mathrm{SiO}_{2}$, superchondritic $\mathrm{Ca} / \mathrm{Al}$ ratio, presence of carbonate). The lack of alkalies could be the result of either loss after impact melting or absence of alkalies in the source.
\end{abstract}

\section{INTRODUCTION}

Angrites constitute a grouplet of achondrites (one fall and seven finds), the petrogenesis of which remains enigmatic. One major feature is their $\mathrm{Ca} / \mathrm{Al}$ ratio, which is in significant excess to the CI value, which in turn is one of the least variable parameters among the solar system objects, either primitive or differentiated. Does this feature result from a specific source material, a particular accretion scenario, or a unique differentiation path? To answer these questions and unravel the angrite enigma, the study of every new specimen available is of particular importance.
According to the early studies of Prinz et al. (1977), Mittlefehldt and Lindstrom (1990), and the more recent finds (Crozaz and McKay 1990; Prinz and Weisberg 1990, 1995; Yanai 1994; Mikouchi et al. 1996; Mittlefehldt et al. 2002; Varela et al. 2002; Kurat et al. 2004), Angra dos Reis, the reference for the grouplet, appears to be unique (possibly a cumulate), while other angrites are generally interpreted as magmatic rocks (see Kurat et al. 2004 for an opposite view).

NWA 1296 is a single lens-shaped stone weighing $810 \mathrm{~g}$ (Figs. 1a and 1b). It was bought by a dealer in the spring of 2001 in Bouarfa, Morocco. The specimen looks fresh, has remnants of the fusion crust, a shiny gray surface (no desert 

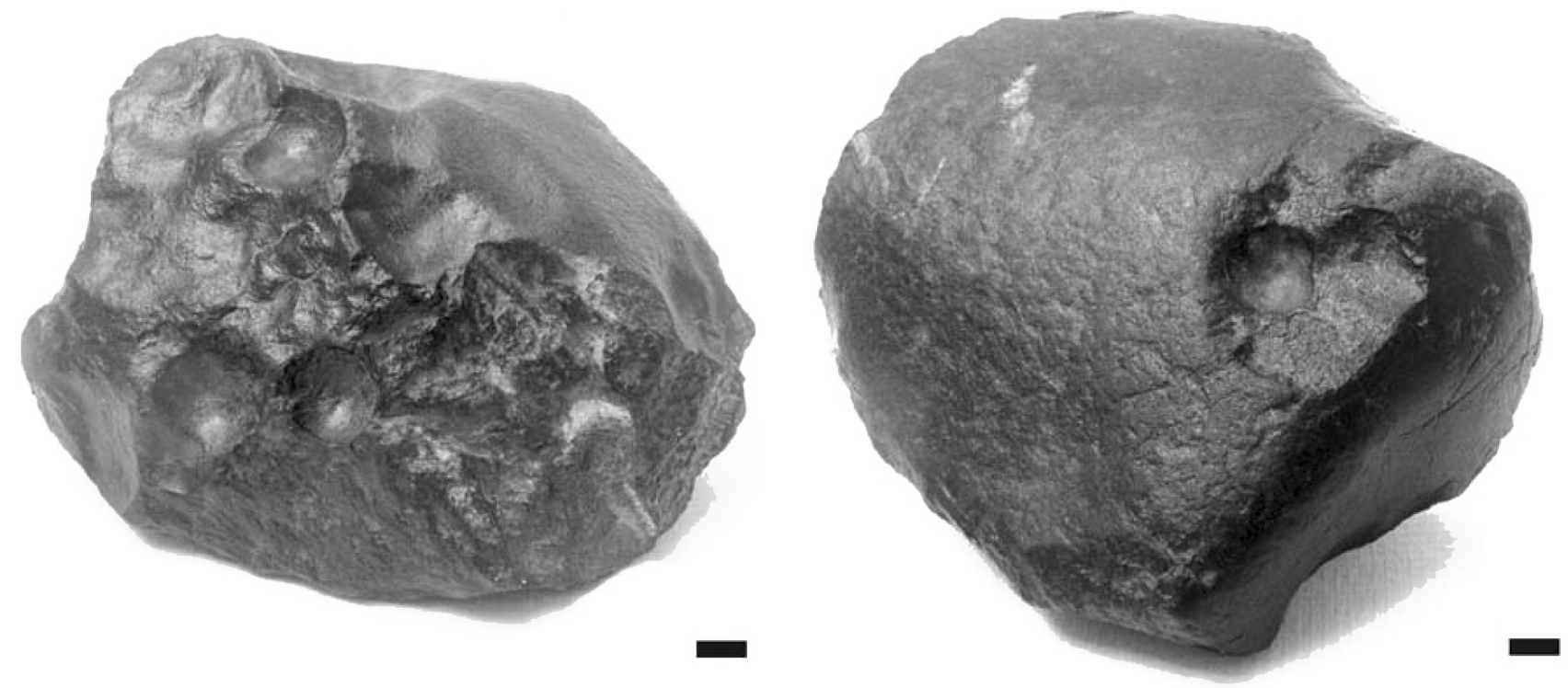

Fig. 1. Views of the whole specimen before sawing. Notice the regmaglypts and carbonates. The scale bar is $1 \mathrm{~cm}$.

varnish), and typical centimetric cusps (regmaglypts) and hemispheric cusps, which suggests centimetric bubbles. No such bubbles were intersected during sawing. Weathering products (such as orange carbonates) are limited to a few spots. These orange spots are believed to result from terrestrial alteration. They overlap white carbonate of primary origin. However, very small amounts of white carbonate are present throughout the rock. Shock features are nearly absent, except for minor fracturing within $1 \mathrm{~mm}$ from the surface. The rock is finely grained and alternating black and white laths can be observed with a lens. On the sawn surface, the interior appears too fine-grained to permit reasonable identification of any phase present.

In this work, we report on the basic mineralogy and petrology of this new find from Morocco. We will show how it relates to the other angrites.

\section{ANALYTICAL METHODS}

The rock was end-cut with a diamond wire saw using ethanol as a lubricant to recover a $60 \mathrm{~g}$ sample. A slice was further sawn to prepare a thin section. The remainder was wrapped in paper and broken with a hammer to prepare chips for chemical analysis. Sawn surfaces and outer crust were discarded and a specimen of $49 \mathrm{~g}$ was preserved.

Petrographic observations and quantitative chemical analyses of the various phases were made on a thin section of NWA 1296 of about $9 \mathrm{~cm}^{2}$ and a polished thick section of about $1 \mathrm{~cm}^{2}$. The procedures are similar to those used for the shergottite NWA 856 (Jambon et al. 2002). Backscattered electron (BSE) images were taken with a JEOL 840A scanning electron microscope (SEM) with an energy dispersive spectrometer (EDS) in Paris. Electron microprobe analyses were performed in Paris (UPMC) and Brest with a Cameca SX50 (WDS). The operating conditions were $15 \mathrm{kV}$ accelerating voltage, with a probe current of $12 \mathrm{nA}$ and a spot size of about $1 \mu \mathrm{m}$ for all phases but carbonates. For carbonate analyses, we used specific conditions, namely a current of $5 \mathrm{nA}$ and a spot size of $4 \mu \mathrm{m}$, to avoid the volatilization of $\mathrm{K}$ under the electron beam. Repeated analyses on the same spots showed that these conditions were acceptable.

A $500 \mathrm{mg}$ fragment was finely ground using a sapphire mortar and pestle. A split $(120 \mathrm{mg})$ was used to determine the major element abundances in Grenoble with inductively coupled plasma atomic emission spectrometry (ICP-AES) (see Barrat et al. 2002). Trace element geochemistry will be reported elsewhere. The modal composition was estimated from the combination of point counting on BSE images, Al Xray mapping, and from a mass balance calculation for the phases and bulk rock composition.

\section{RESULTS}

\section{Petrography}

\section{Optical Examination}

Under the microscope, the texture of the rock appears unusual. Feathery mineral chains appear worm-like, with a gray marrow surrounded by a low relief phase of about $20 \mu \mathrm{m}$ in width and variable length of up to $50 \mu \mathrm{m}$; branching is not common and worms are rather undulatory and sub-parallel to one another. The gray marrow, later identified as single crystals of spinifex-like olivine, could not be determined optically because of their small size; they are overgrown with and surrounded by anorthite microphenocrysts. The chains 


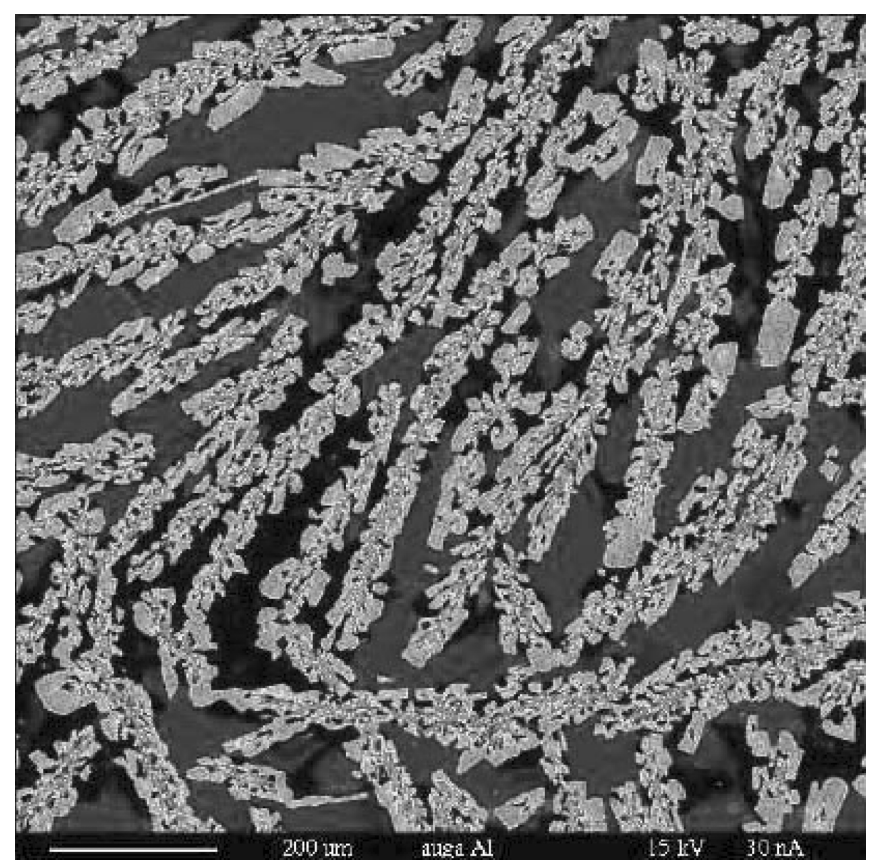

Fig. 2. An $\mathrm{Al} \mathrm{K} \alpha$ view. This image is a K $\alpha$ map of part of the section. Field of view $1 \times 1 \mathrm{~mm}$. Al is the best means for separating the major phases. In the core of the chains, olivine and anorthite are not Clinopyroxenes are gray and olivine and kirschsteinite are black. Since the backbones of the chains are unresolved, they display meaningless colors.

are partly included in large pyroxenes $(50 \times 500 \mu \mathrm{m})$ that make up most of the remaining assemblage. The marrow olivines are monocrystals, whereas the surrounding anorthites are not, despite an overall common orientation.

\section{SEM Examination}

Due to the small size of the crystals, BSE examinations were necessary to achieve an inventory of mineral phases and their mutual relations. This approach was beneficial in producing an X-ray $\mathrm{K} \alpha$ image of $\mathrm{Al}$ (Fig. 2), which provides the best means of separating the major phases. The marrow is made of branched olivines single crystals, so small that they are not resolved at the $2 \mu \mathrm{m}$ level of the X-ray analysis. A BSE view at higher magnification (Fig. 3) provides the details of this particular texture. Each branch is capped by an anorthite crystal with outer planar faces resulting in orientation of anorthite parallel to the axis of chains. This relationship between the two phases is uncommon among magmatic rocks and will be discussed below. The anorthite-olivine chains are separated mostly by long clinopyroxenes or, when in closer proximity, by a fence of equant olivine crystals of comparably small size (about 10-40 $\mu \mathrm{m}$ ). The pyroxene intergrowths are slightly wider $(30-40 \mu \mathrm{m})$ than the chains.

We examined the pyroxenes at high magnification by field emission gun scanning electron microscopy (FEG-SEM) and detected no exsolution features, at least at the scale of a few tens of nanometers.

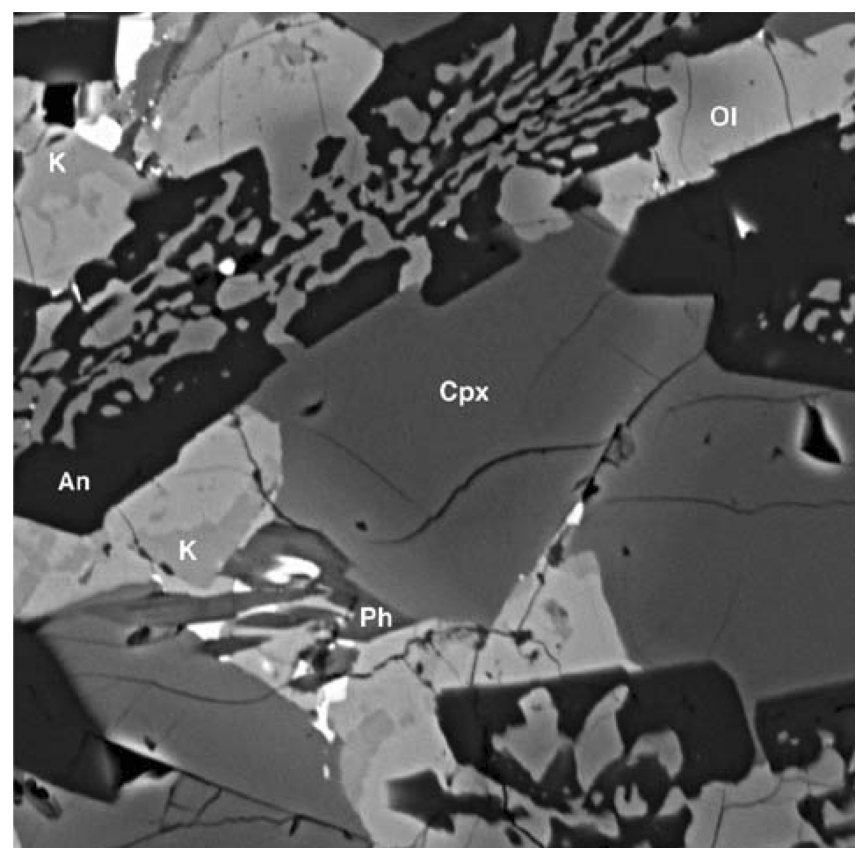

Fig. 3. A BSE view showing the relationship between olivine and anorthite in the core of the chains. Zoning of olivine appears also clearly with its kirschsteinite rim. $\mathrm{Ol}=$ olivine, $\mathrm{Cpx}=$ clinopyroxene, $\mathrm{K}=$ kirschsteinite, $\mathrm{An}=$ anorthite, $\mathrm{Ph}=$ phosphate. The width of view is $0.15 \mathrm{~mm}$.

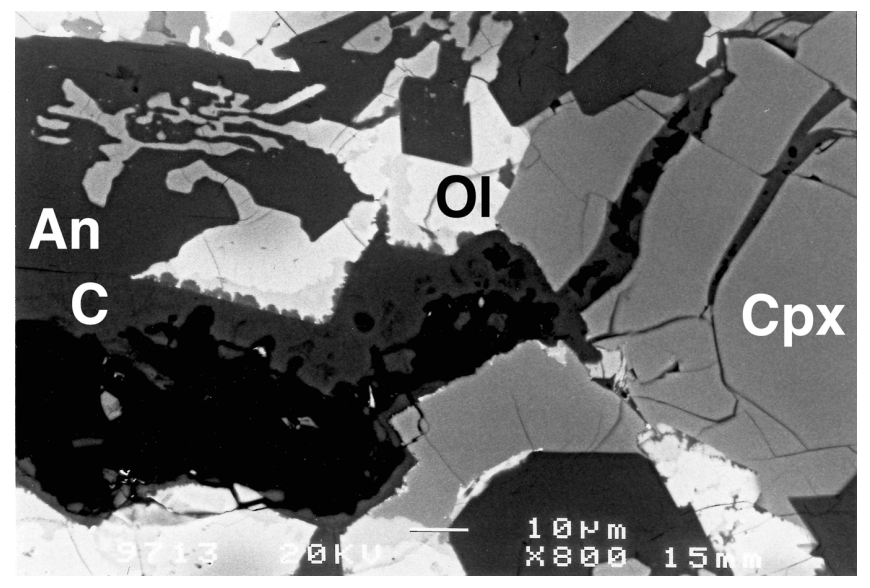

Fig. 4. A BSE image. The contact between kirschsteinite and carbonate C (planar interface) is underscored by a suite of micrometric bubbles indicating probably the partial resorption of kirschsteinite. Notice the channel (black) partly filled and rimmed with porous carbonate. The dead end at upper right indicates that it is not a fracture. The otherwise planar outer face of kirschsteinite against carbonate indicates that carbonate predates resorption of the former.

Anorthite crystallization stopped before the completion of pyroxene and olivine crystallization according to its euhedral shape surrounded by xenomorphic aggregates of either pyroxene or equant olivine. Olivine continued to crystallize with a Fe-rich composition and with a completely different habit (equant and interstitial between pyroxene and anorthite). Olivines frequently overlap the anorthite 


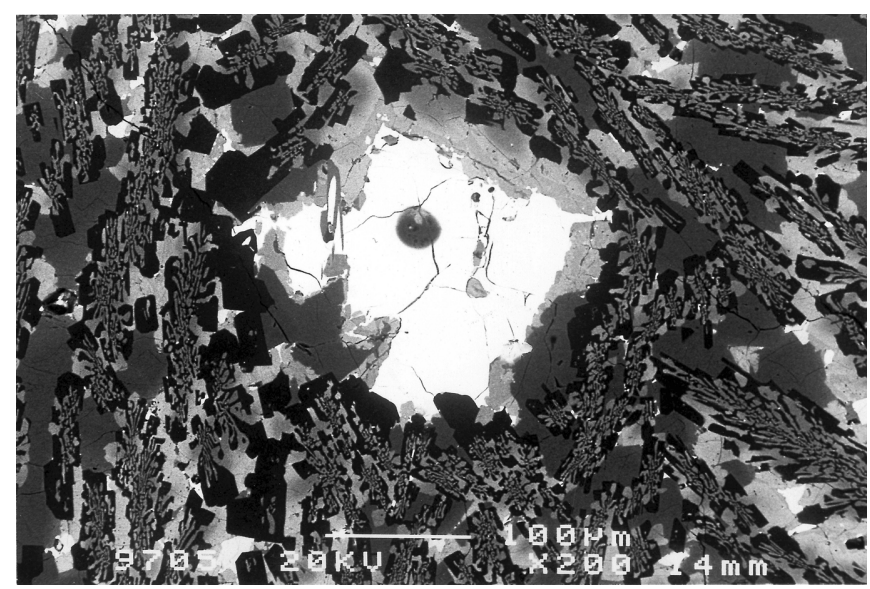

Fig. 5. A BSE image. A crystal of pyrrhotite, surrounded in a coronitic way by olivine, pyroxene, and anorthite, is interpreted as a former liquid droplet. It includes a spherical calcium carbonate inclusion, which indicates that liquid carbonate was trapped inside the liquid sulfide. The fractures connecting the carbonate, which could have been the feeding path for late carbonate filling, are shown to be empty at higher magnification.

microcrysts and expand laterally to form a polycrystalline fence against the chains. In their rims, olivines are overgrown, with idiomorphic contact, or intergrown with kirschsteinite $(\sim 21 \% \mathrm{CaO})-\mathrm{a}$ phase typical of angrites. The boundary between olivine and kirschsteinite can be either planar or bumpy at the micrometer scale. Intergrowths of olivine and kirschsteinite are frequent. The relationship between olivine and kirschsteinite suggests that at least some of the kirschsteinite may be pseudomorphosed olivine. Both olivine and kirschsteinite stopped growing before pyroxene, as in some places the latter appears interstitial between idiomorphic crystals of olivine and kirschsteinite. When kirschsteinite is in contact with carbonate (Fig. 4) its planar outer rim is corroded as if reaction with carbonate resulted in kirschsteinite dissolution. As underlined by pyroxene zonation, crystallization finished in small pockets where pyroxene is interstitial to all other silicate phases with brownish rims due to their $\mathrm{Fe}$ and $\mathrm{Ti}$ contents. Pyroxene can be shown to be the last silicate phase to crystallize as it sometimes appears interstitial to idiomorphic olivine and kirschsteinite.

Accessory minerals appear at the end of the crystallization sequence. Interstitial opaques, titanomagnetite, and pyrrhotite are observed between pyroxene, kirschsteinite, and olivine. Tiny kamacite crystals are observed inside the largest pyrrhotite crystal in the section, probably resulting from exsolution upon crystallization of a sulfide melt. Because of their small size and specific location, phosphates are difficult to observe optically; they are brown and are set against or within the dark Ti- and Fe-rich terminations of pyroxenes. They are commonly associated with pyrrhotite and vesicles, but are also included in the terminations of late pyroxenes (Fig. 3). SEM pictures show that apatite grains are usually included in pyroxene near their ends or interstitial and
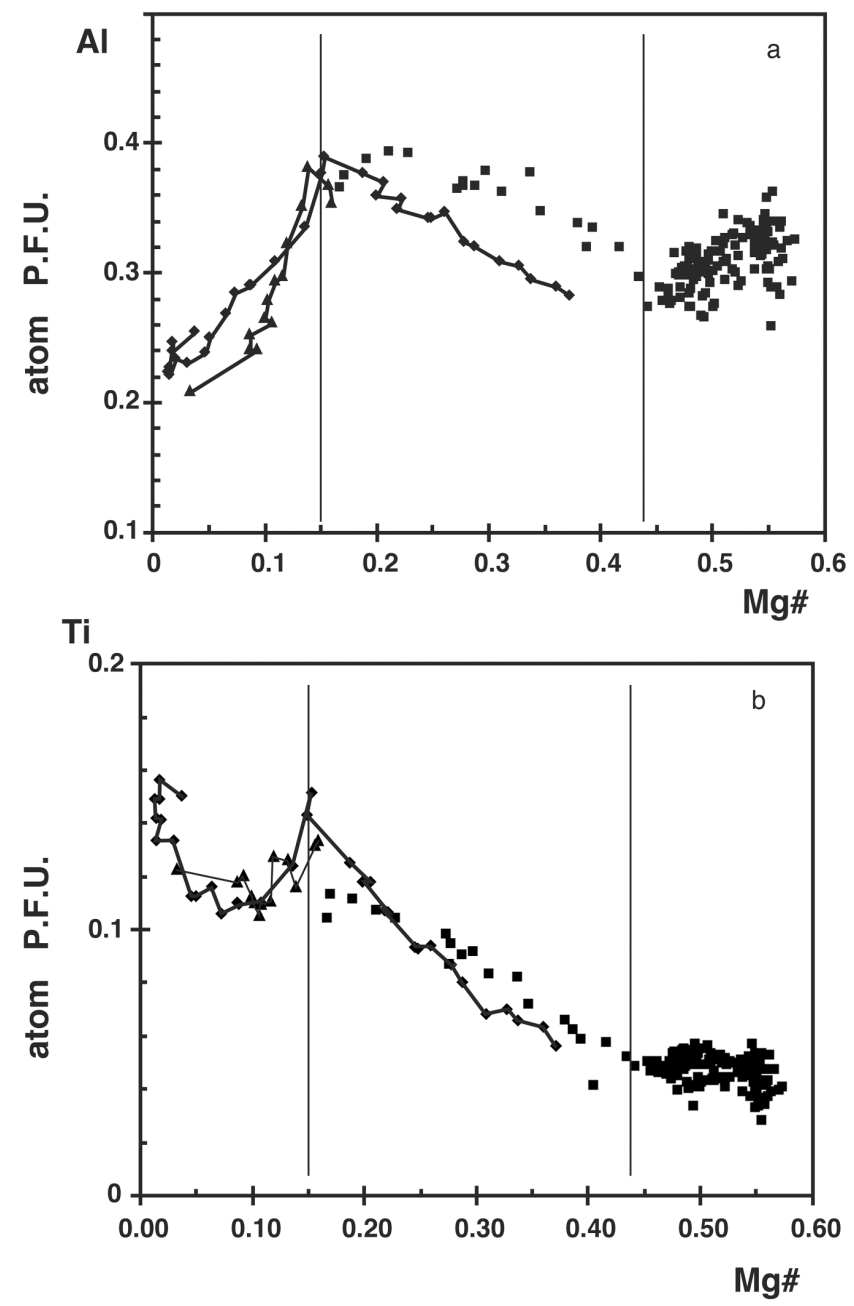

Fig. 6. a) $\mathrm{Al}$ against $\mathrm{Mg} \#$ showing compositional zoning of the phenocrysts. Connected points correspond to two single crystals; $b$ ) same data points showing the corresponding Ti variations.

are associated with vesicles and sulfides. The habit and texture is similar to that described by Kaneda et al (2001) in D'Orbigny. They occur as small chips or thin laths (up to $0.05 \mathrm{~mm}$ in length) and are often skeletal.

Pyrrhotite is associated with the late products of crystallization. A few large spots are surrounded by silicates in a coronitic pattern (Fig. 5), indicating that liquid sulfide was present before the crystallization of both pyroxene and calcic olivine. The largest sulfide globules contain small shapeless inclusions of metal, suggesting exsolution from a crystallizing sulfide melt. Neither the sulfide nor the metal exhibit signs of meteoric alteration. One spherical inclusion of Ca-carbonate was observed in each of two large pyrrhotite crystals. The spherical shape indicates that two immiscible liquids (carbonate and sulfide) were present and quenched. The presence of carbonate globules within unaltered pyrrhotite suggests a primary origin (Fig. 5), especially when considering that pyrrhotite never contains empty bubbles.

Vesicles $(10-50 \mu \mathrm{m})$ are regularly distributed in the final 
pockets of crystallization in association with the opaques. They are usually equant (not spherical, except when included in pyrrhotite); some of them are elongated as if resulting from the coalescence of a number of smaller vesicles or the migration of a fluid phase (Fig. 4). Most commonly, vesicles are empty or contain some calcium carbonate in the amount ranging from tiny chards along the wall to nearly $50 \%$.

When present, carbonate appears to be the remnant of larger globules, given its many small fragments (dismantled vesicle coating?) that occasionally exhibit pores. There are a few transitional occurrences between these vesicles and elongated channels ( $20 \mu \mathrm{m}$ in width). The occurrence of a few veins partly filled with carbonate could also suggest a secondary origin. But the shape of their terminations suggests that they are not filled fractures (2D features) but rather coalesced droplets (1D features). Carbonate is more abundant in there, with a porous, almost spongy aspect. The poor shape of carbonates may result from either sample preparation and/ or petrogenesis. It does not look like the common infiltration of terrestrial carbonate in weathered meteorites recovered in hot deserts. Notice that similar material has been reported to occur in D'Orbigny, especially coating the walls of centimetric vesicles (Jotter et al. 2002).

Some terrestrial carbonate is visible on the outer surface of the sample (Fig. 1). However, its extent is limited to a few spots and its color is orange-brown. It overlaps white carbonate, which we think is of primary origin.

Carbonates are microcrystalline and can be recognized, but not identified, optically.

Additional arguments for the primary origin of carbonates are that the fractures (which could have served as channels for the carbonate included in pyrrhotite) are late features, they do not contain carbonate, and they are not rimmed with oxidation products when crosscutting pyrrhotite. Whatever the origin of carbonate, the presence of vesicles has to be explained and will be discussed below.

\section{Mode}

Having a small-grained rock enables one to study a representative sample of restricted size without statistical difficulty, which is important when a mode has to be determined. In the present case, determining the mode was quite difficult and the results below are only approximate. This is due to the texture of the rock on the one hand and the strongly zoned character of the phases on the other hand. Determining a mode optically is impossible because of the overall small size of the crystals. Therefore, we relied on the $\mathrm{X}$-ray mapping of the sample (Ka line of Al). However, this does not resolve the anorthite-olivine symplectites issue due to the limited resolution of $\sim 2 \mu \mathrm{m}$. BSE images with a higher magnification and resolution permitted estimates to be made of the relative fractions of anorthite and olivine in the symplectic chains. One problem with X-ray mapping is that it is time-consuming and only one image $(1024 \times 1024$ pixels $)$, was obtained for $\mathrm{Al}, \mathrm{Mg}, \mathrm{Ca}, \mathrm{Si}$, and $\mathrm{Fe}$. $\mathrm{Al}$ is the most useful among major elements because of its nearly constant, but different, abundance in the major phases of anorthite, pyroxene, and olivine. The mode was checked using the bulk rock analysis and the composition of the minerals obtained by EMP analysis.

The mode obtained vol\% is as follows: anorthite 32 , olivine 28 , kirschsteinite 3 , pyroxene 34 , Ca phosphate 0.5 , ulvöspinel 1.1, pyrrhotite 0.7 , and vesicles 0.3 . The carbonate of the vesicles is below $0.1 \%$ but may be have been affected by sample preparation. This mode is nearly identical to that reported for Sahara 99555 by Bischoff et al. (2000).

\section{MINERAL COMPOSITIONS}

\section{Pyroxenes}

Pyroxene is a zoned Al-Ti diopside-hedenbergite. Representative compositions are given in Table 1. Pyroxene compositions have been calculated for 4 cations and 6 oxygens to calculate the proportions of $\mathrm{Fe}^{2+}$ and $\mathrm{Fe}^{3+}$. The average $\mathrm{FeO}_{\mathrm{T}} / \mathrm{MnO}$ ratio of 86 is not significantly different from that of the bulk rock (see below) and from that of pyroxene of other angrites (Mikouchi et al. 1995; Mittlefehldt et al. 2002). However, a major difference is the unexpectedly high variability of this ratio in the present sample $(\sigma=90)$. The composition evolves from the core at $\mathrm{En}_{17} \mathrm{Fs}_{27} \mathrm{Wo}_{41} \mathrm{Ca}-\mathrm{Ts}_{10} \mathrm{Ti}$ $\mathrm{Ts}_{6}$ to the rim at $\mathrm{En}_{1} \mathrm{Fs}_{41} \mathrm{Wo}_{40} \mathrm{Ca}-\mathrm{Ts}_{3} \mathrm{Ti}^{-\mathrm{Ts}_{16}}$ in a complex way. Zoning of the pyroxene can be conveniently presented against $\mathrm{Mg} \#(=\mathrm{Mg} / \mathrm{Mg}+\mathrm{Fe})$. The $\mathrm{Al}$ variations are particularly interesting (Fig. 6). Al first decreases until the end of anorthite crystallization. Then Al increases since only olivine and pyroxene co-crystallize. Due to the low activity of $\mathrm{SiO}_{2}$, some $\mathrm{Al}$ is in tetrahedral coordination in a Tschermak molecule. We then observe a sharp break and Al decreases again. A new Alrich phase appears, which progressively scavenges the remaining Al. According to the variations of the other elements, we observe that in the end $(\mathrm{Mg} \#<0.2)$ some $\mathrm{Fe}^{3+}$ enters the tetrahedral site. The abundance of $\mathrm{Fe}^{3+}$ in the pyroxene is not a simple reflection of oxygen fugacity. According to the correlation with $\mathrm{Al}$ it seems to result from crystallochemical control. Even more interesting is the behavior of Ti, which is progressively enriched with Al. The sharp Al decrease is concomitant with that of Ti suggesting that the new phase contains both $\mathrm{Al}$ and $\mathrm{Ti}$. However, there is a major difference between these two elements. Al is exhausted and goes to zero whereas Ti increases again until the end of the crystallization sequence when ulvöspinel precipitates.

Based on Mittlefehldt et al. (2002) and Kurat et al. (2004) results on D'Orbigny, we suggest that this phase might be their enigmatic Ca-Al-Ti-Fe silicate, possibly rhönite, analyzed in D'Orbigny. As it has not been found in our 
Table 1. Representative analyses of pyroxenes.

\begin{tabular}{|c|c|c|c|c|c|c|c|c|c|c|c|c|}
\hline & $\mathrm{C} 4$ & $\mathrm{C} 12$ & C35 & $\mathrm{C} 28$ & $78^{*}$ & 27 & 76 & 57 & 107 & 297 & 256 & 185 \\
\hline $\mathrm{SiO}_{2}$ & 40.63 & 41.95 & 38.98 & 43.70 & 45.62 & 46.34 & 46.44 & 46.52 & 44.49 & 45.73 & 45.46 & 46.82 \\
\hline $\mathrm{TiO}_{2}$ & 4.73 & 3.45 & 3.49 & 2.69 & 2.26 & 1.71 & 1.84 & 1.18 & 2.24 & 1.78 & 1.80 & 1.27 \\
\hline $\mathrm{Al}_{2} \mathrm{O}_{3}$ & 4.51 & 5.90 & 6.54 & 6.82 & 6.67 & 5.97 & 6.01 & 4.59 & 7.09 & 6.35 & 6.53 & 5.74 \\
\hline $\mathrm{Cr}_{2} \mathrm{O}_{3}$ & 0.05 & 0.00 & 0.00 & 0.06 & 0.03 & 0.11 & 0.09 & 0.05 & 0.33 & 0.20 & 0.34 & 0.13 \\
\hline $\mathrm{MgO}$ & 0.22 & 1.10 & 2.73 & 4.32 & 5.48 & 6.02 & 6.29 & 7.02 & 6.97 & 7.53 & 7.79 & 8.30 \\
\hline $\mathrm{FeO}_{\mathrm{T}}$ & 26.53 & 24.57 & 28.63 & 18.99 & 16.83 & 16.54 & 15.93 & 16.88 & 15.34 & 14.89 & 14.49 & 13.91 \\
\hline $\mathrm{MnO}$ & 0.14 & 0.03 & 0.36 & 0.06 & 0.09 & 0.10 & 0.17 & 0.14 & 0.28 & 0.17 & 0.16 & 0.23 \\
\hline $\mathrm{CaO}$ & 21.56 & 22.35 & 18.98 & 22.74 & 22.57 & 23.00 & 22.29 & 22.53 & 22.33 & 23.27 & 22.81 & 23.34 \\
\hline $\mathrm{NiO}$ & - & - & - & - & 0.06 & 0.04 & 0.08 & 0.00 & 0.00 & 0.00 & 0.08 & 0.01 \\
\hline $\mathrm{Na}_{2} \mathrm{O}$ & 0.06 & 0.04 & 0.00 & 0.00 & 0.02 & 0.03 & 0.01 & 0.03 & 0.04 & 0.00 & 0.03 & 0.01 \\
\hline Total & 99.17 & 99.50 & 99.72 & 99.39 & 99.61 & 99.85 & 99.15 & 98.93 & 99.10 & 99.92 & 99.49 & 99.76 \\
\hline $\mathrm{Mg \#}$ & 0.01 & 0.07 & 0.15 & 0.29 & 0.37 & 0.39 & 0.41 & 0.43 & 0.45 & 0.47 & 0.49 & 0.52 \\
\hline $\mathrm{FeO} / \mathrm{MnO}$ & 193 & 827 & 80 & 306 & 193 & 172 & 93 & 120 & 54 & 88 & 89 & 62 \\
\hline $\mathrm{Si}$ & 1.64 & 1.67 & 1.55 & 1.70 & 1.76 & 1.79 & 1.80 & 1.81 & 1.72 & 1.75 & 1.74 & 1.79 \\
\hline $\mathrm{Al}$ & 0.21 & 0.28 & 0.31 & 0.31 & 0.30 & 0.27 & 0.28 & 0.21 & 0.32 & 0.29 & 0.30 & 0.26 \\
\hline $\mathrm{Mg}$ & 0.01 & 0.07 & 0.16 & 0.25 & 0.32 & 0.35 & 0.36 & 0.41 & 0.40 & 0.43 & 0.45 & 0.47 \\
\hline $\mathrm{Fe}$ & 0.90 & 0.82 & 0.95 & 0.62 & 0.54 & 0.53 & 0.52 & 0.55 & 0.50 & 0.48 & 0.47 & 0.44 \\
\hline $\mathrm{Mn}$ & 0.01 & 0.00 & 0.02 & 0.00 & 0.00 & 0.00 & 0.01 & 0.01 & 0.01 & 0.01 & 0.01 & 0.01 \\
\hline $\mathrm{Ca}$ & 0.94 & 0.96 & 0.81 & 0.95 & 0.94 & 0.95 & 0.93 & 0.94 & 0.92 & 0.95 & 0.94 & 0.96 \\
\hline $2 * \mathrm{Ti}$ & 0.29 & 0.21 & 0.23 & 0.16 & 0.13 & 0.10 & 0.10 & 0.06 & 0.13 & 0.10 & 0.10 & 0.07 \\
\hline $\mathrm{Fe}^{2}$ & 0.49 & 0.38 & 0.55 & 0.28 & 0.37 & 0.38 & 0.39 & 0.38 & 0.26 & 0.26 & 0.25 & 0.28 \\
\hline $\mathrm{Fe}^{3}$ & 0.41 & 0.44 & 0.40 & 0.34 & 0.17 & 0.15 & 0.13 & 0.17 & 0.23 & 0.22 & 0.21 & 0.16 \\
\hline
\end{tabular}

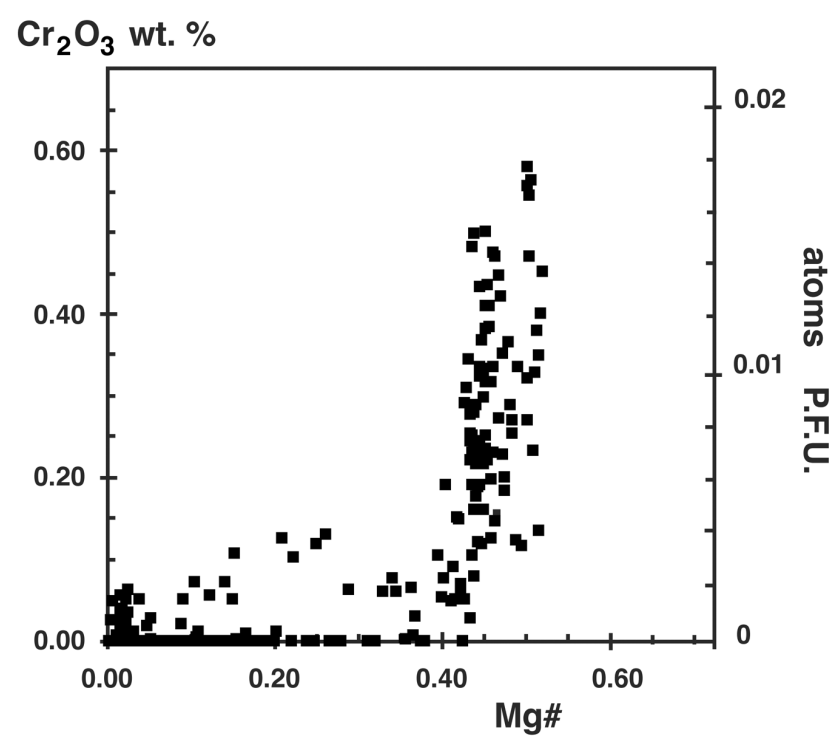

Fig. 7. $\mathrm{Cr}_{2} \mathrm{O}_{3}$ against $\mathrm{Mg} \#$ showing the sharp depletion of $\mathrm{Cr}_{2} \mathrm{O}_{3}$ as pyroxene crystallization proceeds.

section, a subsequent replacement for this phase may exist.

The zoning of $\mathrm{Cr}_{2} \mathrm{O}_{3}$ differs significantly. It is abundant in the core $\left(0.5 \% \mathrm{Cr}_{2} \mathrm{O}_{3}\right)$ and drops below $0.1 \%$ for $\mathrm{Mg \#}$ $<0.45$ (Fig. 7). Pyroxene compositions cannot be represented in the conventional pyroxene quadrilateral because of the significant Tschermak component. Instead, they can be projected from the Tschermak components (both $\mathrm{Ca}$ and $\mathrm{Ti}$ ) onto the En-Fs-Wo plane (Fig. 8). The data points fall close to the Diopside-Hedenbergite join for $\mathrm{Mg \#}<0.45$. When looking more closely at the zoning of pyroxenes, it appears

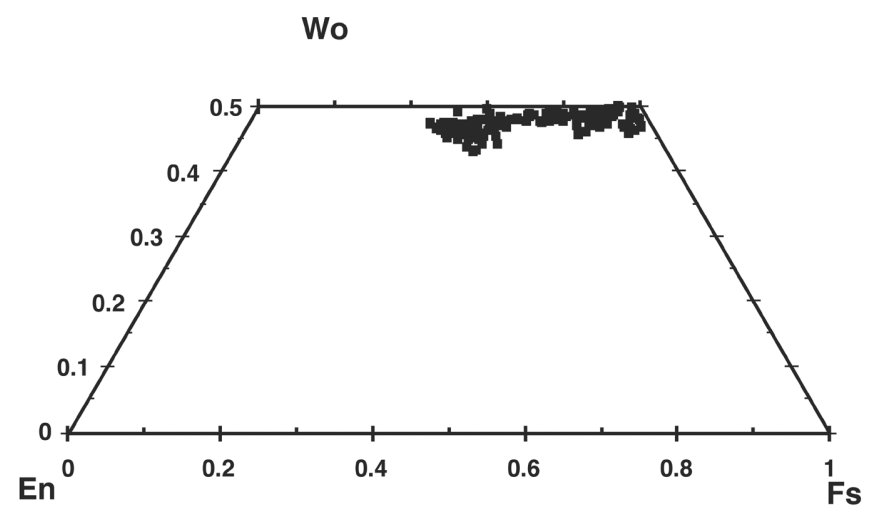

Fig. 8. The Pyroxene quadrilateral is a projection from the Tschermak component onto the En-Fs-Wo triangle. Notice the similarity with the results of Mittlefehldt et al. (2002) for D'Orbigny.

that oscillatory zoning is superimposed on the normal zoning described above, with a wavelength on the order of $10 \mu \mathrm{m}$ (Fig. 9). Oscillatory zoning explains the strong and otherwise unexplained variability of the $\mathrm{FeO} / \mathrm{MnO}$ ratios. We interpret this as a kinetic effect resulting from rapid growth. The pyroxene rims $(\mathrm{Mg} \#<0.05)$ are not in equilibrium with one another. For instance, $\mathrm{CaO}$ varies from 20 to $23 \%, \mathrm{Al}_{2} \mathrm{O}_{3}$ from 4.0 to $5.2 \%$, and $\mathrm{TiO}_{2}$ from 3.5 to $4.9 \%$ without any correlation with $\mathrm{Mg \#}$. This is in agreement with a final crystallization occurring together with other phases in small pockets without communication between them.

\section{Anorthite}

The plagioclase is nearly pure anorthite. Anorthite 
Table 2. Representative analyses of anorthite. All Fe as $\mathrm{FeO}$.

\begin{tabular}{lcrrrrr}
\hline & \multicolumn{1}{c}{4} & \multicolumn{1}{c}{48} & \multicolumn{1}{l}{77} & \multicolumn{1}{l}{78} & \multicolumn{1}{c}{80} \\
\hline $\mathrm{SiO}_{2}$ & 42.78 & 43.18 & 44.76 & 43.13 & 42.41 & 42.09 \\
$\mathrm{Al}_{2} \mathrm{O}_{3}$ & 35.91 & 36.64 & 35.11 & 35.62 & 35.51 & 34.19 \\
$\mathrm{MgO}$ & 0.12 & 0.09 & 0.43 & 0.06 & 0.13 & 0.08 \\
$\mathrm{FeO}$ & 0.80 & 0.97 & 1.24 & 1.57 & 1.76 & 2.03 \\
$\mathrm{CaO}$ & 19.48 & 19.65 & 19.75 & 19.91 & 19.92 & 19.96 \\
$\mathrm{Na}_{2} \mathrm{O}$ & 0.03 & 0.13 & 0.07 & 0.13 & 0.09 & 0.10 \\
$\mathrm{Total}$ & 99.31 & 100.80 & 101.43 & 100.63 & 99.93 & 98.63 \\
$\mathrm{An}$ & 99.7 & 98.8 & 99.4 & 98.9 & 99.2 & 99.1 \\
\hline
\end{tabular}

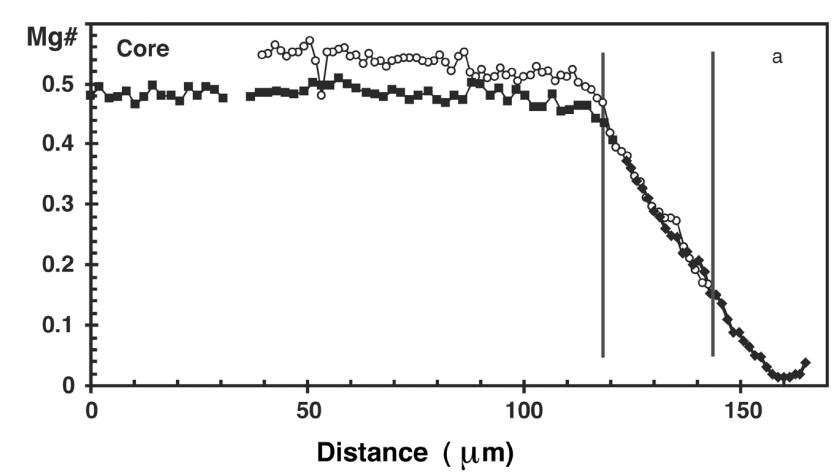

wt \%

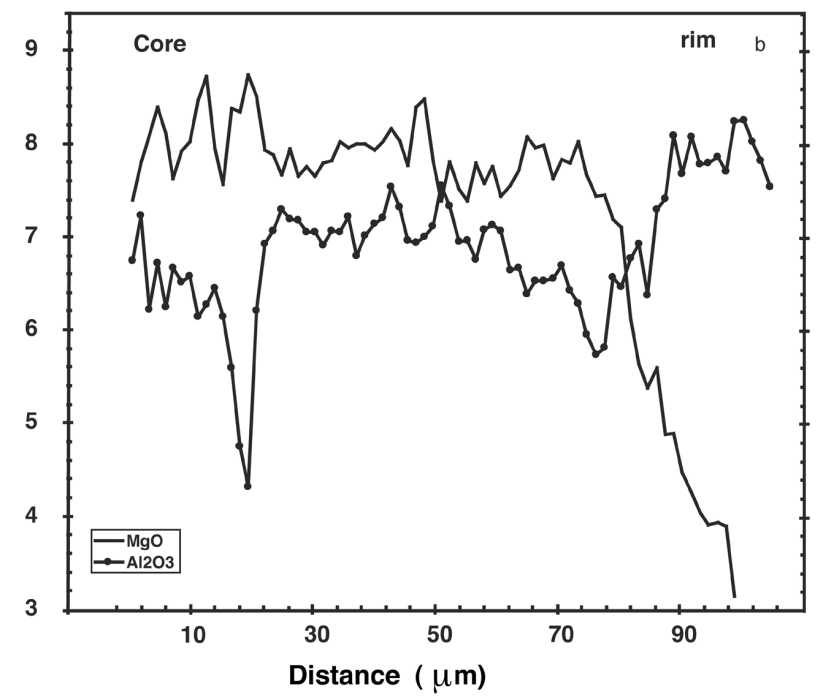

Fig. 9. Zoning of pyroxene: a) normal zoning is very moderate in the core and sharp at the rim for two different crystals. The vertical lines indicate the successive growth stages as in Fig. 6; b) oscillatory zoning in both core and rim of one pyroxene.

crystals are intergrown with olivine in the core of chains and become euhedral at their contact with clinopyroxene. When in contact with vesicles, planar faces could be observed with the SEM (Fig. 10). Representative analyses are reported in Table 2. Notice that $\mathrm{Na}_{2} \mathrm{O}$ is only $0.09 \% \pm 0.03$ and $\mathrm{FeO}_{\mathrm{T}} 1.2 \%$ \pm 0.3 - an abnormally high value for plagioclase. Crystals associated with olivine are zoned in $\mathrm{FeO}_{\mathrm{T}}$ from an estimated $3 \%$ in the core of chains to less than $1 \%$ in their rim. This feature becomes conspicuous with cathodoluminescence as

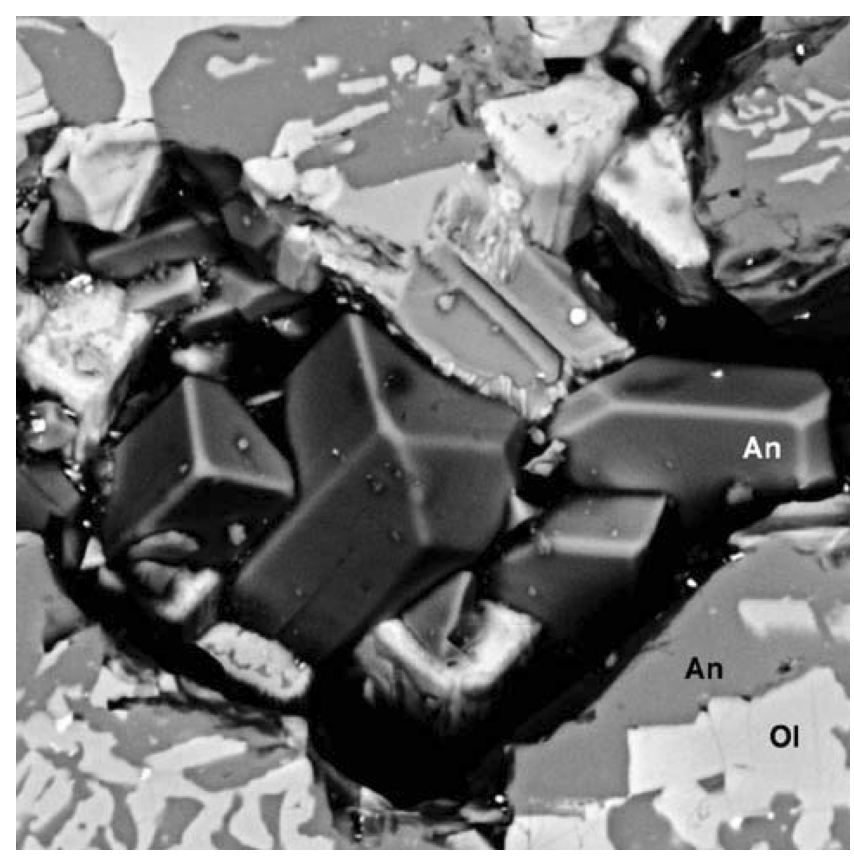

Fig. 10. The presence of microphenocrysts of anorthite (An) in a vesicle at center indicates that its growth stopped at some stage. This possibly represents at a smaller scale the druses of D'Orbigny. A BSE image. The field of view is $50 \mu \mathrm{m}$.

iron oxide quenches luminescence efficiently (Fig. 11). The decrease of $\mathrm{Fe}$ in anorthite as it grows is at odd with a normal crystallization sequence, suggesting that incorporation of $\mathrm{Fe}$ is a kinetic, out of equilibrium feature, in agreement with the symplectic growth with spinifex like olivine.

\section{Olivine and Kirschsteinite}

Two types of olivine crystals are observed (Table 3). The first type are the backbones of feathery chains and intergrown with anorthite (Fig. 3). They are difficult to analyze because of their small size. We estimate their compositions range from $\mathrm{Fo}_{52}$ to about $\mathrm{Fo}_{30}$. This texture corresponds to a fast-growth habit as shown by Donaldson (1976) and Jambon et al. (1992). The second type are microphenocrysts that overgrow the former. No compositional gap exists between the two types. Their Mg\# decreases to $<0.01$ and at the same time their $\mathrm{CaO}$ content increases to $12 \%$ (Fig. 12). Zoning is steady from the cores of chains to the rims of microphenocrysts. The composition of the kirschsteinite is very similar to that reported by Mittlefehldt et al. (2002).

\section{Phosphates}

F-apatite analyses are reported in Table 4; they contain a moderate amount of $\mathrm{FeO}$ (up to $9 \mathrm{wt} \%$ ). The presence of a silicophosphate has been mentioned in three other angrites: Asuka-881371 (Prinz et al. 1995; Warren and Davis 1995), D’Orbigny and Sahara 99555 (Mikouchi et al. 2001; 
Table 3. Representative analyses of olivine and kirschsteinite.

\begin{tabular}{|c|c|c|c|c|c|c|c|c|}
\hline & \multicolumn{5}{|c|}{ Olivine } & \multicolumn{3}{|c|}{ Kirschsteinite } \\
\hline & $140^{*}$ & $48^{*}$ & $291^{*}$ & $270 *$ & $286^{*}$ & $252 *$ & $43 *$ & $99 *$ \\
\hline $\mathrm{SiO}_{2}$ & 34.29 & 33.47 & 32.08 & 31.38 & 30.75 & 30.24 & 29.82 & 30.35 \\
\hline $\mathrm{TiO}_{2}$ & 0.07 & 0.03 & 0.10 & 0.17 & 0.30 & 0.14 & 0.10 & 0.08 \\
\hline $\mathrm{Al}_{2} \mathrm{O}_{3}$ & 0.41 & 0.18 & 0.19 & 0.35 & 0.24 & 0.02 & 0.00 & 0.00 \\
\hline $\mathrm{MgO}$ & 23.00 & 18.06 & 13.43 & 8.67 & 3.99 & 1.86 & 1.34 & 2.53 \\
\hline $\mathrm{FeO}_{\mathrm{T}}$ & 38.44 & 44.73 & 50.46 & 54.28 & 53.84 & 54.37 & 49.61 & 45.86 \\
\hline $\mathrm{MnO}$ & 0.55 & 0.38 & 0.58 & 0.75 & 0.90 & 0.56 & 0.75 & 0.59 \\
\hline $\mathrm{CaO}$ & 1.74 & 1.85 & 2.68 & 4.16 & 9.46 & 12.36 & 16.64 & 19.04 \\
\hline $\mathrm{Na}_{2} \mathrm{O}$ & 0.00 & 0.02 & 0.02 & 0.02 & 0.01 & 0.00 & 0.00 & 0.01 \\
\hline $\mathrm{Cr}_{2} \mathrm{O}_{3}$ & 0.06 & 0.09 & 0.09 & 0.00 & 0.00 & 0.00 & 0.00 & 0.01 \\
\hline $\mathrm{NiO}$ & 0.00 & 0.02 & 0.04 & 0.09 & 0.00 & 0.00 & 0.00 & 0.01 \\
\hline Total & 98.57 & 98.82 & 99.65 & 99.88 & 99.49 & 99.55 & 98.26 & 98.48 \\
\hline $\mathrm{Mg} \#$ & 0.52 & 0.42 & 0.32 & 0.22 & 0.12 & 0.06 & 0.05 & 0.09 \\
\hline $\mathrm{FeO} / \mathrm{MnO}$ & 7 & 0 & 1 & 1 & 8 & 8 & 8 & 7 \\
\hline Fo & 50.2 & 40.6 & 30.8 & 20.6 & 9.7 & 4.5 & 3.3 & 6.0 \\
\hline $\mathrm{Fa}$ & 47.1 & 56.4 & 64.8 & 72.3 & 73.7 & 73.9 & 67.6 & 61.3 \\
\hline $\mathrm{La}$ & 2.7 & 3.0 & 4.4 & 7.1 & 16.6 & 21.6 & 29.1 & 32.7 \\
\hline
\end{tabular}

Table 4. Representative analyses of phosphates.

\begin{tabular}{lrrcrrrr}
\hline \multicolumn{1}{c}{7} & \multicolumn{1}{c}{2.5} & $13 / 1$ & 2.4 & 2.3 & 5 & 1.8 \\
\hline $\mathrm{SiO}_{2}$ & 29.75 & 17.96 & 13.16 & 8.48 & 4.05 & 2.10 & 1.35 \\
$\mathrm{Al}_{2} \mathrm{O}_{3}$ & 3.83 & 0.22 & - & 0.23 & 0.35 & 0.09 & 0.07 \\
$\mathrm{MgO}$ & 0.38 & 0.08 & 0.00 & 0.01 & 0.13 & 0.05 & 0.16 \\
$\mathrm{FeO}$ & 29.71 & 33.77 & 5.96 & 16.14 & 4.25 & 8.26 & 10.14 \\
$\mathrm{MnO}$ & 0.17 & 0.26 & 0.09 & 0.09 & 0.01 & 0.06 & 0.12 \\
$\mathrm{CaO}$ & 23.55 & 28.36 & 47.61 & 39.29 & 46.91 & 44.88 & 43.45 \\
$\mathrm{TiO}_{2}$ & 2.09 & 0.42 & - & 0.62 & 0.34 & 0.04 & 0.08 \\
$\mathrm{Na}_{2} \mathrm{O}$ & 0.08 & 0.02 & 0.04 & 0.11 & 0.33 & 0.48 & 0.30 \\
$\mathrm{P}_{2} \mathrm{O}_{5}$ & 5.04 & 16.23 & 29.46 & 24.54 & 33.18 & 40.73 & 38.24 \\
$\mathrm{Total}$ & 94.60 & 97.31 & 96.33 & 89.52 & 89.54 & 96.71 & 93.94 \\
\hline
\end{tabular}

Table 5. Representative analyses of titanomagnetite; all Fe as $\mathrm{FeO}$.

\begin{tabular}{lrrrr}
\hline & \multicolumn{1}{c}{122} & \multicolumn{1}{c}{148} & \multicolumn{1}{c}{63} & \multicolumn{1}{c}{102} \\
\hline $\mathrm{SiO}_{2}$ & 0.09 & 0.07 & 0.55 & 0.17 \\
$\mathrm{TiO}_{2}$ & 22.50 & 24.52 & 26.38 & 28.40 \\
$\mathrm{Al}_{2} \mathrm{O}_{3}$ & 2.10 & 2.42 & 2.32 & 2.57 \\
$\mathrm{Cr}_{2} \mathrm{O}_{3}$ & 0.01 & 0.00 & 0.00 & 0.00 \\
$\mathrm{MgO}$ & 0.03 & 0.10 & 0.14 & 0.13 \\
$\mathrm{FeO}$ & 66.73 & 62.78 & 63.22 & 63.83 \\
$\mathrm{MnO}$ & 0.20 & 0.49 & 0.18 & 0.19 \\
$\mathrm{CaO}$ & 0.15 & 0.38 & 0.81 & 0.17 \\
$\mathrm{NiO}$ & 0.08 & 0.04 & 0.00 & 0.00 \\
$\mathrm{Total}$ & 91.94 & 90.81 & 93.65 & 95.46 \\
\hline
\end{tabular}

Mittlefehldt et al. 2002). We also obtained such compositions in NWA 1296. However, we believe that in the present case, due to analytical difficulties (small skeletal crystals), such compositions result mostly from an analytical artifact. Most compositions plot between a pure phosphate composition and that of pyroxene (Fig. 13). Due to the small size of the phosphate crystals and their nearly systematic association with or inclusion in pyroxene, this result is all but surprising. Systematic association with late pyroxene indicates that apatite
Table 6. Mean compositions of carbonates. $\mathrm{CO}_{2}$ calculated by stoichiometry $\left(\mathrm{CaO}\right.$ and $\left.\mathrm{K}_{2} \mathrm{O}\right)$.

\begin{tabular}{lrrrr}
\hline & \multicolumn{1}{c}{$\mathrm{A}$} & \multicolumn{1}{c}{$\mathrm{E}$} & \multicolumn{1}{c}{$\mathrm{G}$} \\
\hline $\mathrm{SiO}_{2}$ & 3.39 & 0.48 & 5.39 & 21.85 \\
$\mathrm{MgO}$ & 0.61 & 0.44 & 0.70 & 3.45 \\
$\mathrm{CaO}$ & 45.17 & 54.26 & 47.27 & 35.26 \\
$\mathrm{FeO}$ & 1.04 & 0.90 & 3.46 & 7.78 \\
$\mathrm{MnO}$ & 0.02 & 0.05 & 0.06 & 0.17 \\
$\mathrm{ZnO}$ & - & 0.02 & 0.02 & 0.05 \\
$\mathrm{Na}_{2} \mathrm{O}$ & 0.16 & 0.04 & 0.07 & 0.07 \\
$\mathrm{~K}_{2} \mathrm{O}$ & 5.95 & 1.01 & 0.58 & 0.45 \\
$\mathrm{Subtotal}$ & 57.42 & 57.21 & 57.57 & 69.07 \\
$\mathrm{CO}_{2}$ & 38.27 & 43.11 & 37.42 & 27.92 \\
Total & 95.69 & 100.32 & 94.98 & 96.99 \\
\hline
\end{tabular}

appeared in the latest stages of crystallization when pyroxene was the only remaining silicate to grow. The presence of about $2 \%$ fluorine in apatite is noticeable in addition to about $2 \%$ $\mathrm{SiO}_{2}$. The presence of silica in apatite seems to be real as the analysis of apatite included in pyrrhotite reveals $8 \% \mathrm{SiO}_{2}$ and only $0.3 \% \mathrm{Al}_{2} \mathrm{O}_{3}$. The presence of silica in apatite is a typical feature of carbonate-rich magmatic rocks (Rønsbo 1989) and skarns (Pascal et al. 2001).

\section{Oxides}

The oxide is an ulvöspinel-magnetite solution (Table 5) with the average composition of $\mathrm{Us}_{78} \mathrm{Mt}_{17} \mathrm{Hc}_{5}$ and a range in Us of 72-82. It is interstitial among pyroxenes and calcic olivine-kirschsteinite, as equant crystals of 10-20 $\mu \mathrm{m}$. It does not exhibit exsolution. Unlike in D'Orbigny or Sahara 99555 (Mittlefehldt et al. 2002), we did not find hercynitic spinel. The same is true for the Fe-Ca-Al-Ti silicate (presumably rhönite) mentioned by Mittlefehldt et al. (2002) and Kurat et al. (2004), which was not found here. 


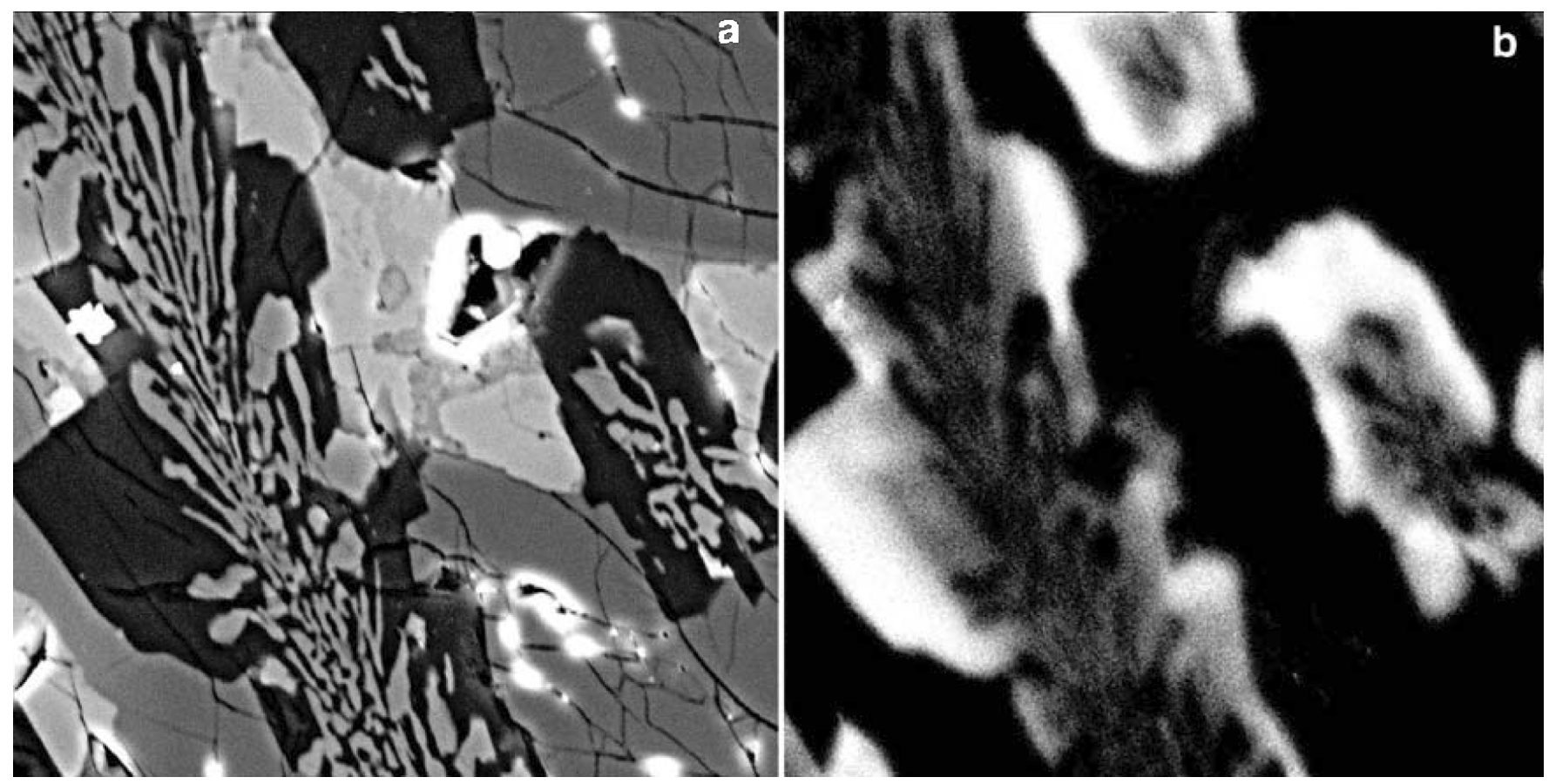

Fig. 11. a) A BSE image, field of view $100 \mu \mathrm{m}$; b) cathodoluminescence image area within (a). Anorthite is strong in the rims and weak in the core. This is related to the iron content of core anorthite, which quenches luminescence.

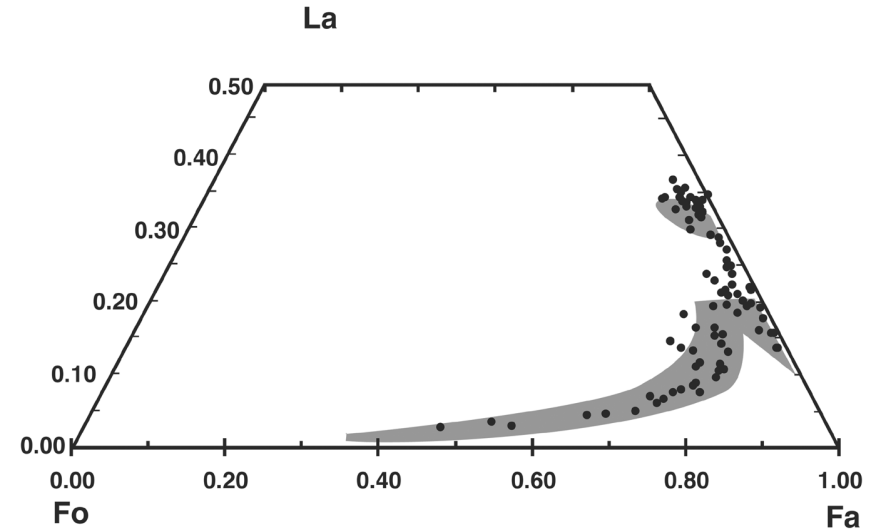

Fig. 12. Olivine compositional range. The composition of olivine and kirschsteinite is presented in the Fo-Fa-La triangle. Notice the similarity with the results obtained for D'Orbigny (shaded field) by Mittlefehldt et al. (2002).

\section{Sulfides}

Small pyrrhotite crystals are associated with the other accessories as final products of crystallization $(\mathrm{Fe}=61 \mathrm{wt} \%$, $\mathrm{Mn}=0.1 \%, \mathrm{Ni}=0.0 \%, \mathrm{Ca}=0.14 \%, \mathrm{~S}=38 \%$ ).

\section{Carbonates}

The carbonate contamination of the rock is negligible as the $\mathrm{Sr}$ abundance is chondritic (e.g., $\mathrm{Sr} / \mathrm{Nd}=15$ ). This would probably not be the case if the carbonate were terrestrial in

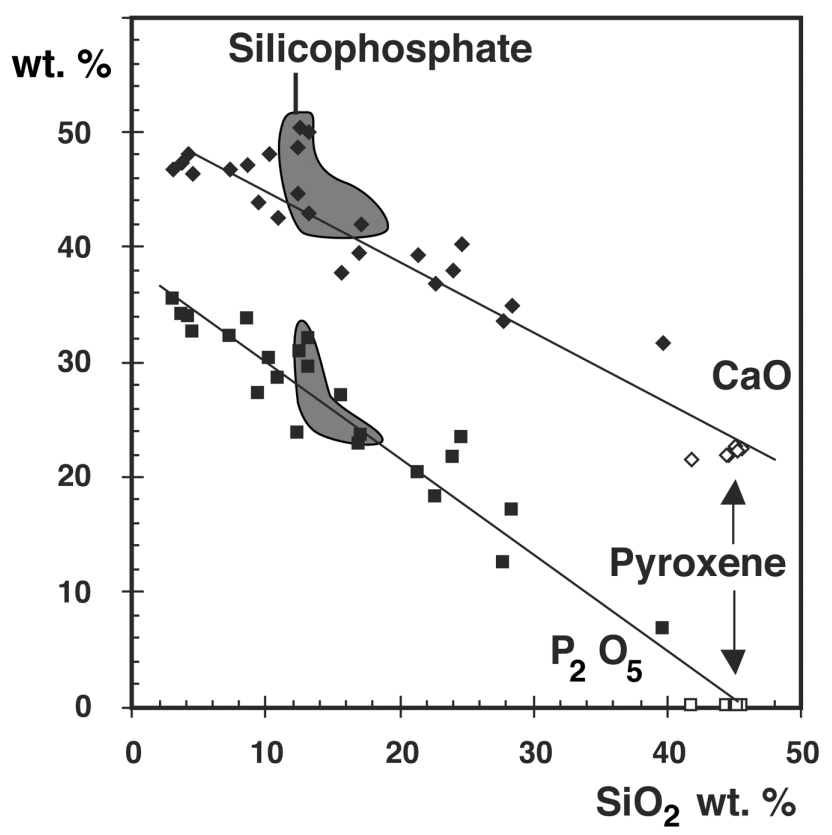

Fig, 13. Correlation of $\mathrm{SiO}_{2}$ versus $\mathrm{CaO}, \mathrm{P}_{2} \mathrm{O}_{5}$ in phosphates. The small size of the phosphates does not permit to properly separate phosphates from silicophosphate (if present) and pyroxene, unlike what is observed in D'Orbigny (shaded areas; data from Mittlefehldt et al. 2002).

origin. The accurate composition of the carbonate was difficult to obtain because the carbonate patches were of a small size, significantly porous, and often below the plane of 
the section. It appears to be mostly Ca carbonate. Even though various compositions with $\mathrm{K}$ carbonate were observed, the $\mathrm{K}_{2} \mathrm{O}$ content of carbonates remains usually below $2 \%$. Because of the very low content of $\mathrm{K}$ in the bulk rock, this was completely unexpected. However, this value might be a gross underestimate since $\mathrm{K}$ carbonate is very unstable under terrestrial conditions because it is highly soluble in water. Therefore, while carbonate may have disappeared in other angrite finds, this is even more likely in the case of Angra dos Reis (the only fall), which was recovered from seawater. The $\mathrm{SiO}_{2}$ content of carbonate is highly variable. The occurrence of silica in the carbonate seems to be real as the $\mathrm{SiO}_{2} / \mathrm{FeO}$ ratio differs from that of either pyroxene, olivine, or kirschsteinite, which may have polluted the analyses. The presence of silica in carbonate is a typical feature of igneous carbonate. A proper and detailed study of the carbonate will be presented in a forthcoming paper.

\section{DISCUSSION}

\section{Crystallization of NWA 1296}

The unusual texture of NWA 1296 suggests that crystallization proceeded as follows:

1. Crystallization of olivine from a melt with a spinifex-like texture. This implies a high degree of supercooling (see Donaldson 1976; Jambon et al. 1992).

2. Nucleation of anorthite in the boundary layer of growing olivine. After a while, the growth rate of both olivine and anorthite decreases, leading to coarser crystals. Anorthite crystallization stops leaving euhedral microcrysts.

3. Olivine continues to grow and becomes enriched in iron. It overlaps the chains and spreads laterally.

4. Immiscible liquid sulfide and carbonate are already present.

5. Aluminous clinopyroxene (rich in $\mathrm{Ca}$ ) starts crystallizing as $\left(\mathrm{Ca}_{1.86} \mathrm{Ti}_{0.1} \mathrm{~A}_{10.3}[\mathrm{Mg}, \mathrm{Fe}]_{1.8}\left[\mathrm{Fe}_{0.2} \mathrm{~A}_{10.2} \mathrm{Si}_{3.6}\right] \mathrm{O}_{12}\right)$ and incorporates progressively the olivine-anorthite chains. The core of pyroxenes contains some chromium, which becomes exhausted when Mg\# becomes lower than 0.40. The composition of the pyroxene is progressively enriched in $\mathrm{Fe}$ and $\mathrm{Ti}$, in a complex way though.

6. Eventually, rhönite crystallizes and soon scavenges the remaining $\mathrm{Al}$ and some of the Ti. Olivine is enriched in $\mathrm{Ca}$ (up to $12 \% \mathrm{CaO}$ ).

7. Apatite is crystallized either enclosed in the terminal pyroxene or interstitially after olivine stopped growing.

8. The crystallization is almost completed. Rhönite is replaced by ulvöspinel. Pyrrhotite crystallizes from the sulfide immiscible droplets. Minor amounts of iron are exsolved from sulfide.

9. Some of the iron-rich olivine boundaries are replaced by kirschsteinite. The remaining $\mathrm{Ca}$ carbonate precipitates in veins and vesicles. Eventually, some of the kirschsteinite is dissolved.

Notice that during crystallization the liquid may be buffered in $\mathrm{CaO}$ as calcic silicates precipitate according to:

$$
\text { liquid }+\mathrm{CaCO}_{3}=\mathrm{CaO} \text {-liquid }+\mathrm{CO}_{2}
$$

This permits to explain the high $\mathrm{Ca}$ activity from the beginning to the end of the crystallization sequence and the anomalous $\mathrm{Ca} / \mathrm{Al}$ ratio of this rock. The porous aspect of carbonate contained in vesicles is the expression of its destabilization. In addition, microvesicles are contained in the various crystals. As an exception, the carbonate enclosed in sulfide appears sound, as $\mathrm{Ca}$ is not soluble in sulfide which does not precipitate any calcic phase. Its spherical shape and microcrystalline state indicates that it was a liquid in molten sulfide before being quenched.

The presence of liquid carbonate suggests that the source contained significant amounts of carbonate or that the carbonate was incorporated to the magma during its ascent. In the first case, it implies that the pressure was high enough to enable the stability of carbonate at high pressure and temperature.

To conclude this section, the very fast cooling rate is in agreement with the possibility that NWA 1296 is a clast-free impact melt. Notice that unlike in some of the other angrites (e.g., D’Orbigny, Lewis Cliff [LEW] 87051, Asuka-881371, and NWA 1970), highly magnesian olivine xenocrysts have not been found. This interpretation is in agreement with the interpretation of Mikouchi et al. (2003) for NWA 1670, another angrite with shocked olivine xenocrysts. The absence of alkalies in all angrites could result from their volatilization upon impact.

\section{Petrogenetic Relationships among Angrites}

D’Orbigny, Sahara 99555, and NWA 1296 have similar bulk compositions (Table 7). They exhibit slight differences in their mineralogy (phase compositions, absence of hercynitic spinel, and rhönite in NWA 1296), which we explain by the out-of-equilibrium crystallization path in NWA 1296. LEW 87051 and Asuka-881371 cannot be related to the other angrites by petrogenetic processes such as melting or crystal fractionation but rather by addition of olivine xenocrysts to angritic melts (Prinz et al. 1990; McKay et al. 1995; Mikouchi et al. 1996).

One common feature of all angrites is their high $\mathrm{Ca}$ abundance, which is reflected in their odd mineralogy and their high $\mathrm{Ca} / \mathrm{Al}$ ratio. It was advocated previously that this results from spinel fractionation (Mittlefehldt and Lindstrom 1990; Mittlefehldt et al. 2002), which is in agreement with the experimental work of Jurewicz et al. (1993). However, why this is a feature specific of angrites (e.g., compared to eucrites) remains to be explained. Even though we cannot 
Table 7. Composition of angrites. Batch melting is for $49 \%$ melting of a pseudo CV source with $\mathrm{SiO}_{2}$ adjusted. Back FC is calculated melt starting from NWA 1296 composition after incremental additions of equilibrium olivine.

\begin{tabular}{lcccccc}
\hline & NWA 1296 & D'Orbigny & Sahara 99555 & $\begin{array}{l}\text { Batch } \\
\text { melting }\end{array}$ & $\begin{array}{l}\text { Back } \\
\text { FC }^{\mathrm{c}}\end{array}$ & $\begin{array}{l}\text { Melilitite } \\
\text { Nyiragongo }^{\mathrm{d}}\end{array}$ \\
\hline $\mathrm{SiO}_{2}$ & $(39)$ & 38.4 & 38.6 & 38.36 & 38.48 & 36.31 \\
$\mathrm{Al}_{2} \mathrm{O}_{3}$ & 12.18 & 12.4 & 12.5 & 8.67 & 7.48 & 11.54 \\
$\mathrm{FeO}_{\mathrm{T}}$ & 25.00 & 24.7 & 23.1 & 24.54 & 24.46 & 11.90 \\
$\mathrm{MnO}$ & 0.28 & 0.28 & 0.26 & 0.46 & 0.17 & 0.21 \\
$\mathrm{MgO}$ & 6.71 & 6.49 & 7.04 & 18.33 & 18.83 & 6.40 \\
$\mathrm{CaO}$ & 14.65 & 15 & 15.1 & 6.98 & 9.00 & 16.73 \\
$\mathrm{Na}$ & 0.028 & 0.017 & 0.016 & 0.01 & 0.02 & 4.32 \\
$\mathrm{~K}_{2} \mathrm{O}$ & $<0.03$ & 0.005 & 0.005 & - & - & 4.14 \\
$\mathrm{P}_{2} \mathrm{O}_{5}$ & 0.17 & 0.16 & 0.15 & 0.59 & 0.10 & 2.19 \\
$\mathrm{TiO}_{2}$ & 0.93 & 0.89 & 0.91 & 0.42 & 0.57 & 2.56 \\
$\mathrm{Cr}_{2} \mathrm{O}_{3}$ & 0.068 & 0.045 & 0.046 & - & - & - \\
$\mathrm{Total}$ & $(100)$ & 98.38 & 97.72 & 100.04 & 99.16 & 96.30 \\
\hline
\end{tabular}

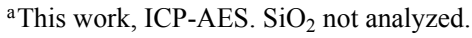

bMittlefehldt et al. (2002).

${ }^{\mathrm{c}}$ Calculated compositions.

dDemant et al. (1994).

dismiss the former possibility, we suggest another one. The high $\mathrm{Ca} / \mathrm{Al}$ ratio might result from $\mathrm{Ca}$ excess instead of $\mathrm{Al}$ substraction. The occurrence of $\mathrm{Ca}$ carbonate found in both D'Orbigny (Jotter et al. 2002; Kurat et al. 2004) and NWA 1296 - a unique feature among achondrites - supports this hypothesis. The presence of $\mathrm{Ca}$ carbonate during partial melting should change the phase relationships and the decomposition of carbonate during decompression clearly results in $\mathrm{CaO}$ enrichment of the melt.

Finally, we point out that angrites should in no way be qualified as being basaltic. Shergottites and eucrites have true basaltic compositions which define a crystallization path with silica as a final product. This contrasts with the behavior of angritic melts that are strongly undersaturated in silica, exhibit specific phase compositions (e.g., fassaitic pyroxene, calcic olivine), and finish their crystallization path with kirschsteinite as a final product.

As long as the number of known angrites was very small, it was impossible to speculate reasonably on the petrogenetic processes prevalent in their formation. With the recent finds, it appears that NWA 1296, D'Orbigny, and Sahara 99555 are the most common compositions (Table 7), with Asuka881371 and LEW 87051 being related to similar compositions by addition of olivine xenocrysts and with LEW 86010 not so different from the former.

\section{Why Angrites Are Not Melts from CV Chondrites}

One can read in Mittlefehldt et al. (1998) "the petrogenesis of LEW 86010 seems well understood. The bulk of the rock is similar to that produced by partial melting of $\mathrm{CM}$ or (especially) $\mathrm{CV}$ chondrites at oxygen fugacities of about one $\log$ unit above the iron-wüstite buffer (Jurewicz et al. 1993)." This point is of great importance since one should conclude then that the angrite parent body is in some way consanguineous with $\mathrm{CV}$ chondrites. We disagree with this interpretation and reject the possibility that angrites are derived by melting from a $\mathrm{CV}$ composition for the following reasons.

1. Angrites are derived from a source that segregated a core. Such a source differs from a chondritic composition, especially in its $\mathrm{FeO}_{\mathrm{T}}$ (but also $\mathrm{MgO}$ ) abundance. The deficiency in siderophile elements (Kurat et al. 2004), including Ni in Fo90 olivines, and noble metals, is best explained by core segregation. It is not observed in $\mathrm{CV}$ chondrites.

2. Carbonaceous chondrite compositions are not expected to form a significant core as only a small amount of iron is combined as sulfide, the remainder being combined with oxygen and no metal being present.

3. Because of their markedly specific chemistry and isotopic compositions (Greenwood et al. 2003), all angrites must be explained by derivation from one and the same parent body. The presence in some angrites (e.g., Asuka-881371, LEW 87051, and NWA 1670) of highly magnesian olivines ( $\mathrm{Mg} \#$ in the range $0.92-0.75$ ) cannot be reconciled with melting from a source having a $\mathrm{CV}$ chondritic $\mathrm{MgO} / \mathrm{FeO}$ ratio of 0.80 . Again, achondrites with highly magnesian olivines are typical of parent bodies having segregated a core of significant size, like the Earth, and cannot be produced from CV compositions.

4. Olivine in equilibrium with a melt of $\mathrm{CV}$ or $\mathrm{CM}$ composition (complete melting) is about Fo81. If only partial melting of a CV composition occurs the argument is even stronger: olivine in equilibrium with the melt will have a lower Fo content. In other words, a parent body of $\mathrm{CV}$ or CM composition cannot produce Fo90 olivine as is observed in some of the angrites. Finally, the oxygen 
isotopic composition of angrites falling on a welldefined mass fractionation line (Greenwood et al. 2003) cannot be reconciled with $\mathrm{CM}$ or $\mathrm{CV}$ compositions, which fall significantly below that line. No petrogenetic process can move the isotopic composition away from a mass fractionation line. Finally, the CV model does not explain the alkali deficiency of angrites. The same is true for the presence of magmatic carbonates.

We must conclude that according to the works on the recently discovered angrites and the new isotopic results, the former hypothesis formulated by Jurewicz et al. (1993) and Longhi (1999) is no more tenable.

\section{Toward a Model of Angrite Petrogenesis}

We can summarize the constraints to the petrogenesis of angrites as follows:

- The parent body must have the suitable composition to form highly magnesian olivines after core formation, either as a melting residue or as cumulates from a mafic melt.

- In the second stage, these highly magnesian olivines may (Asuka-881371, D'Orbigny, LEW 87051, and NWA 1670) or may not (e.g., NWA 1296 or Sahara 99555) be collected by angritic melts.

As we believe that our understanding of angrite petrogenesis can benefit from a reasonable modeling and such a model is proposed below. The major questions we try to answer are: what is the source composition, the degree of partial melting, and the degree of fractional crystallization?

\section{Source Composition}

We start from a chondritic source. Which particular composition should we select? Major differences among chondrites are expressed in their:

- Amount of oxygen (oxidation state of iron).

- Amount of iron and refractory elements.

For the purpose of the exercise and in the absence of further strong constraints on the very nature of the chondritic source, we decided to relieve the first constraint in the following way. We take a set of average chondritic compositions (e.g., Wasson and Kallemeyn 1988) and adjust the amount of oxygen to obtain a $\mathrm{MgO} / \mathrm{FeO}$ ratio of 1.5 , corresponding to the ratio of a melt in equilibrium with $\mathrm{Fo}_{90}$ olivine. Excess iron is supposed to form the core. Doing this, we assume that $\mathrm{Fo}_{90}$ olivines correspond to crystallization following complete melting of the source. If the melt were produced by partial melting (not complete), the bulk composition would exhibit a higher $\mathrm{MgO} / \mathrm{FeO}$ ratio. Excess alkalies and sulfur are further eliminated since the former are volatiles and are severely depleted in angrites and the latter is assumed to go to the core, but this adjustment is marginal.

We obtain a series of pseudo-chondritic compositions

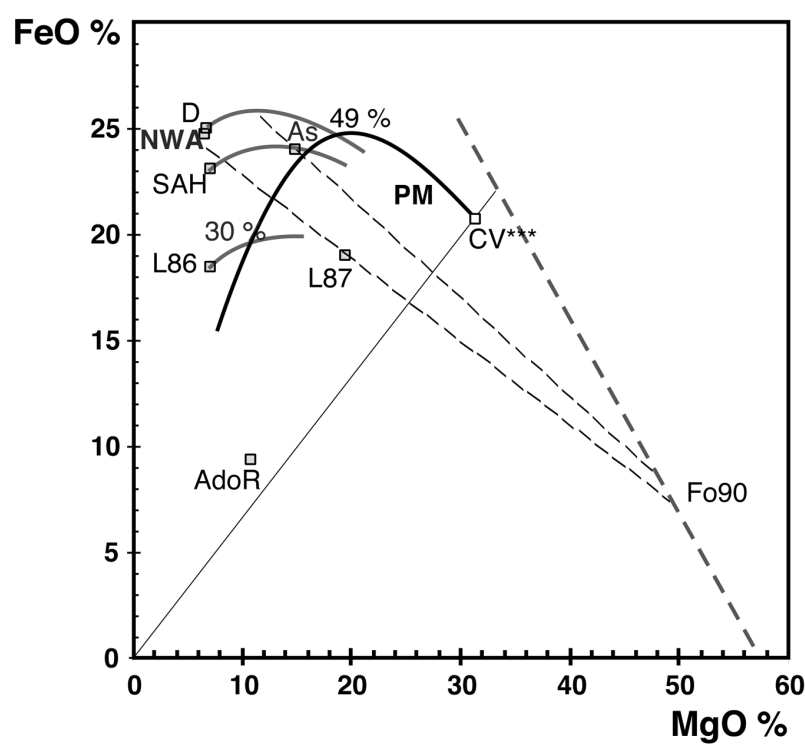

Fig. 14. Batch partial melting curve from a modified $\mathrm{CV}^{* * * *}$ source and three fractional crystallization paths from angritic compositions. For convenience, the intersections of the two paths are displayed in the $\mathrm{MgO}: \mathrm{FeO}$ space but a common $\mathrm{SiO}_{2}$ value at the intersection is observed once the source composition is properly selected (see text). The dashed lines are mixing lines with olivine. The heavy dashed line is the locus of olivine compositions. The percentages are the fractions of partial melting at the intersection with fractional crystallization curves.

having all the same $\mathrm{MgO} / \mathrm{FeO}$ ratio but with varied chemical compositions which translate into variable $\mathrm{MgO}, \mathrm{FeO}$, and $\mathrm{SiO}_{2}$ concentrations essentially. In a subsequent step according to the adequacy of the solution, we will consider modifying the source composition.

\section{Partial Melting}

In order to assess the degree of melting, we calculate the compositions of melts in equilibrium with olivine assuming batch partial melting. This approach is justified by the fact that, at very low silica contents, melt will be in equilibrium with olivine only.

The compositions of residual olivines are fixed and the compositions of the melts are calculated.

Starting from pseudo-chondritic compositions normalized to $\mathrm{MgO} / \mathrm{FeO}=1.5$, we obtain a set of curves which slightly depart from one another. Partial melt compositions are displayed in Fig. 14. No such curve permits to reach angritic compositions. At this stage this is not problematic since, after partial melting, fractional crystallization is expected as will be shown below, and eventually lead to an angritic composition.

However, considering the $\mathrm{SiO}_{2}$ composition of melts we face a serious problem. Angritic liquids are depleted in $\mathrm{SiO}_{2}$ : they evolve with constant or decreasing $\mathrm{SiO}_{2}$ contents implying that the precipitating solid was at least as $\mathrm{SiO}_{2}$-rich as 
the melt. Olivine contains about $39 \% \mathrm{SiO}_{2}$, which indicates that the melt had a $\mathrm{SiO}_{2}$ content of about $38 \%$ at most (which is also the $\mathrm{SiO}_{2}$ content of NWA 1296, D'Orbigny and Sahara 99555).

This point is illustrated while starting from a pseudo $\mathrm{H}$ chondrite composition, an average case, with a $\mathrm{SiO}_{2}$ content of $43.8 \%$. Upon partial melting by $30 \%$, a melt with $56.2 \%$ silica is obtained.

Olivine fractionation cannot lead to an angritic composition with a lower silica content. Therefore, the source must be poorer in silica.

Among chondrites, $\mathrm{CV}$ yield the lowest silica content but still too high. We will come back to this point below.

\section{Fractional Crystallization}

Since partial melting alone provides no solution to the problem, fractional crystallization must be considered. The degree of partial melting being not a priori known, we therefore suggest the following strategy. Starting from an angritic composition, we calculate backward successive parent liquids by stepwise addition of olivine in equilibrium with melts.

NWA 1296, Sahara 99555, and LEW 86010 exhibit slightly different compositions, suggesting variable degrees of fractionation.

Backward evolution lines should cross partial melting curves in the compositional space. To make it simple we consider the $\mathrm{FeO}: \mathrm{MgO}$ subspace and check that, at the intersection, other components, especially silica, are equal for both the partial melts and the liquid of fractional crystallization. At this point, we calculate the fraction of partial melting and the extent of fractionation.

\section{RESULTS: PARTIAL MELTING FOLLOWED BY FRACTIONAL CRYSTALLIZATION}

\section{Silica Content in the Source}

No pseudo-chondritic composition (normalized to $\mathrm{MgO} /$ $\mathrm{FeO}=1.5$ ) permits to reach an angritic composition. All compositions are too rich in silica. Since CV composition is the closest to an acceptable one, we subtract the appropriate silica amount to reach a solution in the $\mathrm{SiO}_{2}: \mathrm{MgO}: \mathrm{FeO}$ space. For the three typical angrites (NWA 1296, Sahara 99555 and LEW 86010) a reasonable solution is obtained for melting fractions of 49,43 , and $30 \%$ respectively, followed by fractional crystallization (see Table 7). We notice that these melting fractions are rather high, which is in agreement with the hypothesis of olivine being the only residual phase. The most interesting point is that from a single source and by conventional processes, three different angrite compositions are obtained. In addition, the source contains the Fo90 olivines necessary to explain LEW 87051, D'Orbigny and NWA 1670.

\section{$\mathrm{CaO}$ and $\mathrm{Al}_{2} \mathrm{O}_{3}$ Abundances}

Calculated partial melts (and their sources) exhibit chondritic $\mathrm{CaO} / \mathrm{Al}_{2} \mathrm{O}_{3}$ since olivine crystallization does not affect this ratio and because of the high degree of partial melting spinel is not residual. The angritic $\mathrm{CaO} / \mathrm{Al}_{2} \mathrm{O}_{3}$ value is superchondritic. This could be obtained by either $\mathrm{CaO}$ enrichment or $\mathrm{Al}_{2} \mathrm{O}_{3}$ depletion (or both). When calculated and observed values are compared (Table 7), $\mathrm{Al}_{2} \mathrm{O}_{3}$ ratio appears too high and the $\mathrm{CaO} / \mathrm{Al}_{2} \mathrm{O}_{3}$ ratio too low in the batch melting composition. Assuming a CV abundance in the ultimate source (relative to $\mathrm{MgO}$ ), we conclude that two processes are necessary: $\mathrm{Al}_{2} \mathrm{O}_{3}$ depletion might result from spinel fractionation as suggested previously (Mittlefehldt and Lindstrom 1990; Mittlefehldt et al. 2002) and in agreement with the low $\mathrm{Cr}$ content of angritic melts; the excess $\mathrm{CaO}$ might result from a $\mathrm{CaCO}_{3}$ contribution. Actually the latter has been found in Sahara 99555, D'Orbigny, and NWA 1296. If a CV source composition is not warranted, we notice that the orders of magnitude of the $\mathrm{Ca}$ and $\mathrm{Al}$ concentrations are both correct, which would not be the case for other chondritic types.

We can summarize the results of our calculation as follows: in a model of partial melting followed by fractional crystallization angritic melts can be generated if:

- A chondritic source segregated a core in the first stage of differentiation to yield a $\mathrm{MgO} / \mathrm{FeO}$ ratio of 1.5 .

- Such a source must have a lower than chondritic $\mathrm{SiO}_{2} /$ $\mathrm{MgO}$ ratio.

- The odd $\mathrm{Ca} / \mathrm{Al}$ ratio may eventually be explained by late spinel fractionation and/or Ca-carbonate incorporation.

Among the above points the low $\mathrm{SiO}_{2} / \mathrm{MgO}$ is a serious difficulty.

At the very large degrees of melting required (30-50\%) the residual phases will be olivine (mostly) and orthopyroxene. A silicate melt should become mechanically unstable in its residue at fractions on the order $5-15 \%$, not more, and therefore the significance of the above calculation is questionable. The angritic melt contains only $38 \% \mathrm{SiO}_{2}$, less than a chondritic source composition (after core segregation) and less than the residue (olivine and orthopyroxene) which, because of simple mass balance considerations, appears impossible. Because of this overwhelming difficulty we suggest an alternative explanation to angrite genesis. A similar difficulty with the low silica content is met for terrestrial melilitites. One such composition is compared with the composition of NWA 1296 in Table 7. The overall similarity is striking, the major differences being with the excess iron in angrites and the excess alkalies and phosphorus in the melilitite.

The slightly different amount of silica is not a difficulty as will be seen below. Further similarities exist such as the association of melilitites with carbonatites and the superchondritic $\mathrm{CaO} / \mathrm{Al}_{2} \mathrm{O}_{3}$ ratio of 1.4. This interpretation is further supported by the specific chemistry of apatite in angrites, which is similar to that of alkalic terrestrial rocks 
(Rønsbo 1989). The absence of alkalies in angrites is the last serious difficulty. It could be the result of volatile depletion in the parent body, but we prefer a secondary loss of alkalies after impact melting. This possibility is illustrated by the composition of terrestrial impact melts in the presence of carbonate, as in the case of the Haughton crater. For silica poor compositions (less than $50 \% \mathrm{SiO}_{2}$ ), some Ca carbonate is preserved while alkalies are severely lost (Osinski and Spray 2001). In addition, the texture of the carbonate is not unlike that observed in NWA 1296. If we subtract alkalies from a melilitic composition, its silica content is increased from about $36 \%$ to about $39 \%$ the value of angrites. This indicates that the silica content of the primary angrite melt could have been substantially lower, a point that was not considered in experimental studies. The possibility that the high cooling rate of angrites is due to impact melting is supported by the evidence of shock melting and quenching in NWA 1670 (Mikouchi et al. 2003).

We can now consider that angritic melts with their low silica and anomalous $\mathrm{CaO} / \mathrm{Al}_{2} \mathrm{O}_{3}$ ratio result from melting of a peridotite in the presence of carbonate. In this case, the phase equilibria are completely different from that prevailing in the absence of carbonate. Silicate melts rich in carbonate are generated at high pressure and carbonate is released as the pressure decreases. This permits the derivation of melts very low in silica still in equilibrium with silicates other than olivine (e.g., pyroxenes).

\section{CONCLUSIONS}

Our model angrite petrogenesis is certainly not final but a number of difficulties are solved while others are clearly delineated.

The overall chemistry suggests a kinship with $\mathrm{CV}$ chondrites, but simple derivations from $\mathrm{CV}$ chondrites meets three overwhelming difficulties:

1. The oxydized state of CVs does not permit to form a significant metallic core in contradiction with the siderophile-depleted composition of angrites.

2. The silica content of any chondritic source is too high to produce angritic melts. A low silica content of the parent body is required and could be explained by volatilization of silica (angrites are severely depleted in volatiles), but the presence of $\mathrm{CaCO}_{3}$ contradicts this hypothesis. Entrapment of $\mathrm{Si}$ in the core is another possibility that has been suggested for the Earth's mantle. Under oxydizing conditions, however, $\mathrm{Si}$ is not siderophile, except possibly at high pressure.

3. The oxygen isotopic composition of $\mathrm{CV}$ chondrites does not match that of angrites.

The specificity of angrites, namely their superchondritic $\mathrm{CaO} / \mathrm{Al}_{2} \mathrm{O}_{3}$ ratio, is difficult to explain in a simple partial melting/fractional crystallization model. Our petrogenetic model and the similarity with terrestrial melilitites suggest that the presence of $\mathrm{CaCO}_{3}$ might be the key. Melting in the presence of carbonate generates low $\mathrm{SiO}_{2}$ melts with superchondritic $\mathrm{CaO} / \mathrm{Al}_{2} \mathrm{O}_{3}$ ratios at moderate fractions of melting. The presence of olivine xenocrysts in some of the angrites and the texture of rapid cooling associated with the absence of alkalies support a final stage of extensive impact melting. The presence of druses in D'Orbigny suggests that they formed by condensation from a gas (Varela et al. 2003; Kurat et al. 2004). We may agree in some way with this suggestion: after a giant impact the temperature might be so high that melt and gas will be mixed together. Upon cooling, some gas may be trapped and crystallization may lead to the formation of druses.

Finally, due to the unique composition, mineralogy, and texture of angrites, no simple conventional model is expected to provide a suitable solution to their petrogenesis.

Acknowledgments-Insightful reviews by M. Varela, A. Bischoff, and T. Mikouchi significantly improved the manuscript. The authors are indebted to the generous donation of more than $50 \mathrm{~g}$ by Moroccan Imports. A CNESCNRS-INSU grant of PNP program is acknowledged. The Naturhistorisches Museum of Wien is thanked for a loan of a section of D'Orbigny and NWA 1296 meteorites, and for a loan of a section of Sahara 99555. I. Martinez and P. Agrinier pointed out the similarities to the Haughton crater rocks.

Editorial Handling-Dr. Urs Krähenbühl

\section{REFERENCES}

Barrat J. A., Gillet P., Sautter V., Jambon A., Javoy M., Göpel C., Lesourd M., and Petit E. 2002. Petrology and geochemistry of the basaltic shergottite NWA 480. Meteoritics \& Planetary Science 37:487-501.

Bischoff A., Clayton R. N., Markl G., Mayeda T. K., Palme H., Schultz L., Srinivasan G., Weber H. W., Weckwerth G., and Wolf D. 2000. Mineralogy, chemistry, noble gases and magnesium isotopic compositions of the angrite Sahara 99555 (abstract). Meteoritics \& Planetary Science 35:A27.

Crozaz G. and McKay G. 1990. Rare earth elements in Angra dos Reis and Lewis Cliff 86010, two meteorites with similar but distinct magma evolutions. Earth and Planetary Science Letters 97:369381.

Demant A., Lestrade P., Lubala R. T., Kampunzu A. B., and Durieux J. 1994. Volcanological and petrological evolution of Nyiragongo volcano, Virunga volcanic field, Zaire. Bulletin of Volcanology 56:47-61.

Donaldson C. H. 1976. An experimental investigation of olivine morphology. Contributions to Mineralogy and Petrology 57: 187-213.

Jambon A., Barrat J. A., Sautter V., Gillet P., Göpel C., Javoy M., Joron J. L., and Lesourd M. 2002. Djel Ibone, the new basaltic shergottite North West Africa 856: Petrology and geochemistry. Meteoritics \& Planetary Science 37:1147-1164.

Jambon A., Lussiez P., Clocchiatti R., and Weisz J. 1992. Olivine growth rates in a tholeiitic basalt: An experimental study of melt inclusions in plagioclase. Chemical Geology 96:277-287.

Jotter R., Jagoutz E., Varela M. E., Zartman R., and Kurat G. 2002. 
$\mathrm{Pb}$ isotopes in glass and carbonate of the D'Orbigny angrite (abstract). Meteoritics \& Planetary Science 37:A73.

Jurewicz A. J. G., Mittlefehldt D. W., and Jones J. H. 1993. Experimental partial melting of the Allende CV and Murchison (CM) chondrites and the origin of asteroidal basalts. Geochimica et Cosmochimica Acta 57:2123-2139.

Kaneda K., Mikouchi T., Saito A., Sugiyama K., Oshumi K., Mukai M., Osaka T., Miyata Y., Nakai M., Kasama T., Chikami J., and Miyamoto M. 2001. Mineralogy of unique calcium silicophosphates in angrites (abstract \#2127). 32nd Lunar and Planetary Science Conference. CD-ROM.

Longhi J. 1999. Phase equilibrium constraints on angrite petrogenesis. Geochimica et Cosmochimica Acta 63:573-585.

McKay G., Crozaz G., Mikouchi T., and Miyamoto M. 1995. Exotic olivine in Antarctic angrites Lewis Cliff 87051 and Asuka881371 (abstract). Meteoritics 30:543-544.

Mikouchi T., Miyamoto M., and McKay G. A. 1996. Mineralogical study of angrite Asuka-881371: Its possible relation to angrite LEW87051. Proceedings of the NIPR Symposium on Antarctic Meteorites 9:174-188.

Mikouchi T., Takeda H., Miyamoto M., Ohsumi K., and McKay G. A. 1995. Exsolution lamellae of kirschsteinite in magnesium-iron olivine from an angrite meteorite. American Mineralogist 80: 585-592.

Mikouchi T., McKay G., Koizumi E., Monkawa A., and Miyamoto M. 2003. Northwest Africa 1670: A new quenched angrite (abstract). Meteoritics \& Planetary Science 38:A115.

Mikouchi T., Kaneda K., Miyamoto M., Sugiyama K., and Ohsumi K. 2001. Micro Raman spectroscopy of unknown calcium silicophosphates in angrite meteorites (abstract). 11th Annual V. M. Goldschmidt Conference.

Mittlefehldt D. W. and Lindstrom M. M. 1990. Geochemistry and genesis of the angrites. Geochimica et Cosmochimica Acta 55: $77-87$.

Mittlefehldt D. W., McCoy T. J., Goodrich C. A., and Kracher A. 1998. Non-chondritic meteorites from asteroidal bodies. In Planetary materials, edited by Papike J. J. Washington D.C.:
Mineralogical Society of America. pp. 4-1-4-195.

Mittlefehldt D. W., Killgore M., and Lee T. 2002. Petrology and geochemistry of D'Orbigny, geochemistry of Sahara 99555, and the origin of angrites. Meteoritics \& Planetary Science 37:345369.

Osinski G. R. and Spray J. G. 2001. Impact-generated carbonate melts: Evidence from the Haughton structure, Canada. Earth and Planetary Science Letters 194:17-29.

Pascal M. L. et al. 2001. The melilite-bearing high-temperature skarns of the Apuseni Mountains, Carpathians, Romania. The Canadian Mineralogist 39:1405-1434.

Prinz M., Keil K., Hlava P. F., Berkley J. L., Gomes C. B., and Curvello W. S. 1977. Studies of Brazilian meteorites. III. Origin and history of the Angra dos Reis achondrite. Earth and Planetary Science Letters 35:317-330.

Prinz M., Weisberg M. K., and Nehru C. E. 1990. LEW 87051, a new angrite: Origin in a Ca-Al-enriched eucritic planetesimal (abstract)? 20th Lunar and Planetary Science Conference. pp. 979-980.

Prinz M. and Weisberg M. K. 1995. Asuka-881371 and the angrites: Origin in a heterogeneous, CAI-enriched, differentiated, volatiledepleted body (abstract). Antarctic Meteorites 20:207-210.

Rønsbo J. G. 1989. Coupled substitution involving REEs and $\mathrm{Na}$ an $\mathrm{Si}$ in apatites in alkaline rocks from the Ilimaussaq, South Greenland, and its petrological implication. American Mineralogist 74:896-901.

Warren P. H. and Davis A. M. 1996. Consortium investigation of the Asuka-881371 angrite: Petrographic, electron microprobe and ion microprobe observations (abstract). Antarctic Meteorites 20: 257-260.

Wasson J.T. and Kallemeyn G.W. 1988. Composition of chondrites. Philosophical Transactions of the Royal Society of London A 325:535-544.

Yanai K. 1994. Angrite Asuka-881371: Preliminary examination of a unique meteorite in the Japanese collection of Antarctic meteorites. Proceedings of the NIPR Symposium on Antarctic Meteorites 7:30-41. 